\title{
Imaging of Total Ankle Arthroplasty: Normal Imaging Findings and Hardware Complications
}

\author{
Imran M. Omar, MD ${ }^{1}$ Samir F. Abboud, MD ${ }^{1}$ Jonathan M. Youngner, MD ${ }^{1}$ \\ ${ }^{1}$ Department of Radiology, Northwestern University Feinberg School \\ of Medicine, Chicago, Illinois \\ Semin Musculoskelet Radiol 2019;23:177-194. \\ Address for correspondence Imran M. Omar, MD, Department of \\ Radiology, Northwestern University Feinberg School of Medicine, 676 \\ North Saint Clair Street, Suite 800, Chicago, IL 60025 \\ (e-mail: iomar@nm.org).
}

\begin{abstract}
End-stage ankle osteoarthritis often significantly impacts patients' quality of life. This can be managed surgically either by ankle arthrodesis or total ankle arthroplasty (TAA). Although ankle arthrodesis is considered by some as the standard-of-care surgical option for this condition, it restricts range of motion and may lead to accelerated osteoarthritis of neighboring joints. Better understanding of ankle biomechanics, the biological effects of orthopaedic devices, and new surgical techniques have led to significant improvements in the designs of TAAs, and over the last several decades TAA

Keywords

- ankle

- tibiotalar

- arthroplasty

- imaging

- complications has been used increasingly to treat patients with end-stage tibiotalar osteoarthritis. However, complication and ultimate failure rates remain greater than those seen with total knee and hip arthroplasty, and imaging is often critical in determining whether a prosthesis is beginning to fail. As a result, imagers should be familiar with the basic types of TAAs in clinical use, the normal radiographic appearances, as well as the common complications seen with this procedure.
\end{abstract}

End-stage ankle osteoarthritis is an often debilitating condition that significantly impacts a patient's mobility and quality of life. The true prevalence of ankle osteoarthritis is unknown, but it is estimated that $\sim 11 \%$ of patients with knee osteoarthritis ${ }^{1}$ and $\sim 1 \%$ of the world population has ankle osteoarthritis. ${ }^{2,3}$ In addition, $~ 90 \%$ of cases are posttraumatic, and it may have an increasing prevalence with greater participation in sports. ${ }^{4}$ In the United Kingdom alone, $\sim 29,000$ visits per year are made by patients with ankle osteoarthritis seeking treatment from foot and ankle orthopaedic surgeons. ${ }^{5}$ Traditionally in patients who have failed conservative measures, ankle arthrodesis has been the gold standard surgical option to reduce pain and restore some quality of life. However, ankle arthrodesis leads to gait dysfunction and increased stress on the adjacent joints that can lead to several complications including nonunion, malalignment, infection, and accelerated osteoarthritis of adjacent joints. $^{6-9}$

First described by Lord and Marotte in 1973, total ankle arthroplasty (TAA) has been increasingly used as an alternative to arthrodesis to decrease pain and restore mobility to the tibiotalar joint. ${ }^{10}$ Initial designs had high rates of failure that led to nearly complete abandonment of TAA. However, newer generation designs have demonstrated much improved results and a gradual increase in the number of TAAs performed. ${ }^{2,11}$ By 2010, 13,000 TAAs had been performed in the United States, ${ }^{8}$ and the rate of TAAs in the United States had increased from 2.4 per 100,000 admissions between 1997 and 2003 to 3.5 per 100,000 admissions between 2004 and $2010 .^{12}$ This represents a $46 \%$ increase in usage rate.

Similar increases have been seen in other countries as well. For example, the UK National Joint Registry noted an increase in TAAs from $\sim 400$ in 2010 to nearly 700 in $2016 .{ }^{13}$ Roukis and Prissel collected the published data from all countries that reported their numbers of TAAs in a national registry. They found that between 2000 and 2006, 1,549 TAAs were performed in these countries, whereas 2,431 TAAs were performed between 2007 and 2011, and 911 TAAs were performed in 2011 alone. ${ }^{14}$ In contrast, the usage rate of ankle arthrodesis has remained relatively stable in a similar time frame. ${ }^{15}$ The sustained increase in the performance of TAA has
Issue Theme Arthroplasties and MSK Reconstructions; Guest Editors, Alice S. Ha, MD and Mihra S. Taljanovic, MD, PhD, FACR
Copyright (C) 2019 by Thieme Medical Publishers, Inc., 333 Seventh Avenue, New York, NY 10001, USA. Tel: +1(212) 584-4662.
DOI https://doi.org/ 10.1055/s-0038-1677466. ISSN 1089-7860. 
been attributed to the development of newer devices that have resulted in substantially decreased complication rates as well as a greater number of trained foot and ankle specialists who offer this technically challenging surgery.

This article describes the differences in the main device designs of TAAs with a discussion of improvements in biomechanics that have led to improved outcomes, as well as the indications/contraindications and imaging strategies used to assess these devices.

\section{Prosthesis Types}

Currently 14 U.S. Food and Drug Administration (FDA) approved ankle arthroplasty systems are available (due to our geographic location, discussion is limited to those devices approved in the United States, some of which are now rarely used or no longer available but remain of historical significance). ${ }^{16}$ Initial first-generation designs mimicked the hip prosthesis, with a highly constrained two-part balland-socket configuration. Implantation included near-total talar bony resection and subtalar arthrodesis. Early clinical outcomes with this first-generation design were largely unacceptable, with high degrees of loosening, osteolysis, and subsidence that were attributed to design flaws related to poor understanding of ankle biomechanics. This necessitated a high degree of revision, and subsequently this type of prosthesis fell out of favor. ${ }^{10,17}$ It is likely that such early unsatisfactory results led to many centers largely abandoning TAA in clinical practice, possibly reflected in the large gaps in FDA-approved designs in the 1980s, 1990s, and early 2000s. ${ }^{18}$

With subsequent designs, construction was tailored with an eye toward decreasing the extent of bony resection required for implantation as well as decreasing the degree of constraint, a reflection of the complexity of normal ankle biomechanics. ${ }^{19,20}$ These prosthetic designs are commonly distinguished on the basis of the number of components involved. The so-called second-generation devices are com- posed of two components, and the third-generation devices are composed of three, although this definition can often be variable in the literature, further complicated by manufacturers referring to "generations" within their lines of products.

The number of components can be more simply determined by the relationship of the polyethylene (PE) spacer to the tibial base plate. If the PE component is locked to the base plate, the prosthesis is two component (also referred to as “fixed bearing")(-Fig. 1). A freely mobile PE spacer results in a three-component design (also referred to as "mobile bearing") (-Fig. 2). ${ }^{21}$ The freely mobile three-component design carries the possible advantage of requiring less bone resection during implantation, at the expense of increased risk for PE spacer dislocation. Of the different types of TAAs, failure rates are highest in the constrained design group, with lesser degrees of loosening in the nonconstrained group. ${ }^{22-25}$ Historically, these groups were further subdivided on the basis of the manner of fixation to bone and the materials used in device construction, although these distinctions may be of less clinical utility currently.

Fixation denotes the means by which the arthroplasty is bonded to the native bone. First-generation devices used cement fixation that required a larger bone resection and may have contributed to the increased complication rates associated with these prostheses. Additionally, as a polymethylmethacrylate cement, the polymerization of bone cement is an exothermic reaction that could theoretically lead to thermal soft tissue damage. Notable differences have been demonstrated between cemented and cementless fixation; cemented prostheses have had aseptic loosening rates reportedly as high as $76 \%$, whereas loosening in cementless prostheses of comparable design was reported between $0 \%$ and $23 \%{ }^{26,27}$ Multiple techniques are used by the various manufacturers to enhance cementless fixation, ranging from the utilization of porous materials to biomimetic surface coatings. ${ }^{28}$ Although cementless techniques have become the preferred method of fixation, for all but the STAR ankle
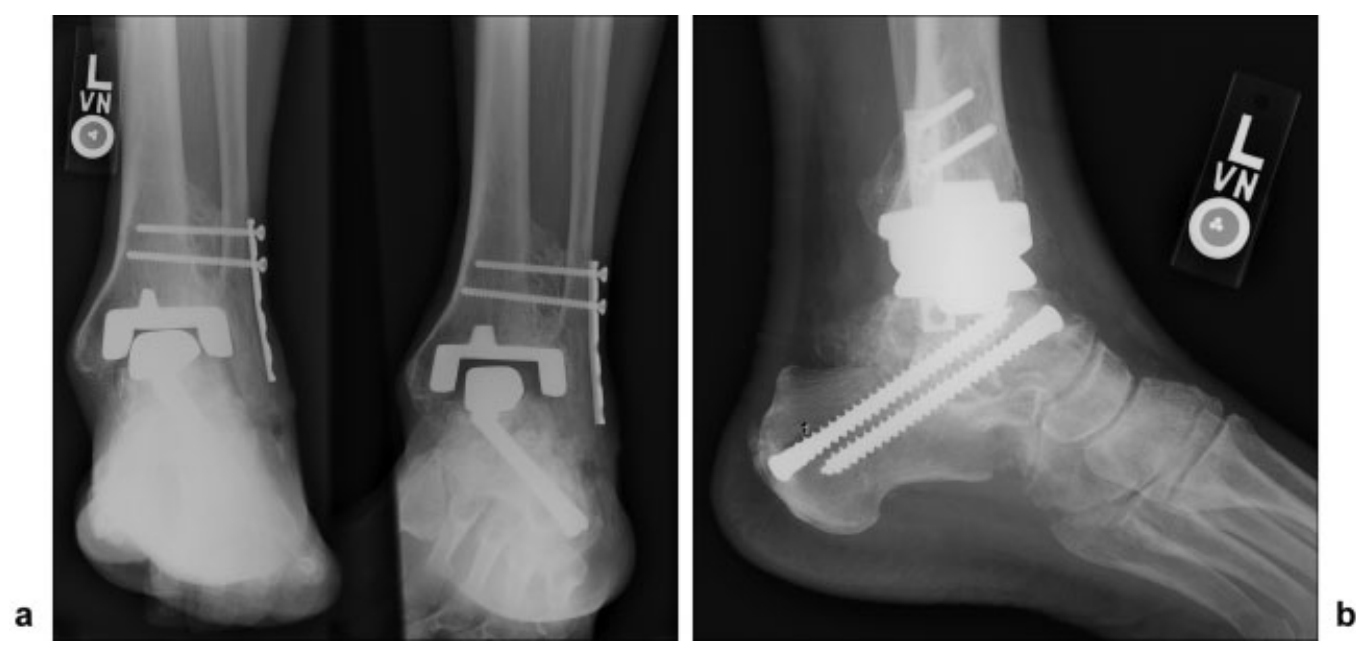

Fig. 1 Fixed-bearing total ankle arthroplasty (TAA). (a) Anteroposterior and oblique, as well as (b) lateral radiographs of the ankle in a 76-yearold man who has a cementless TAA with the Agility system. The device has a tibiofibular tray with a fixed lucent spacer and a talar dome component. To insert the prosthetic components correctly, a fibular osteotomy followed by syndesmotic fixation is performed. The talar dome component does not necessarily have to be centrally positioned within the tibiotalar component. 

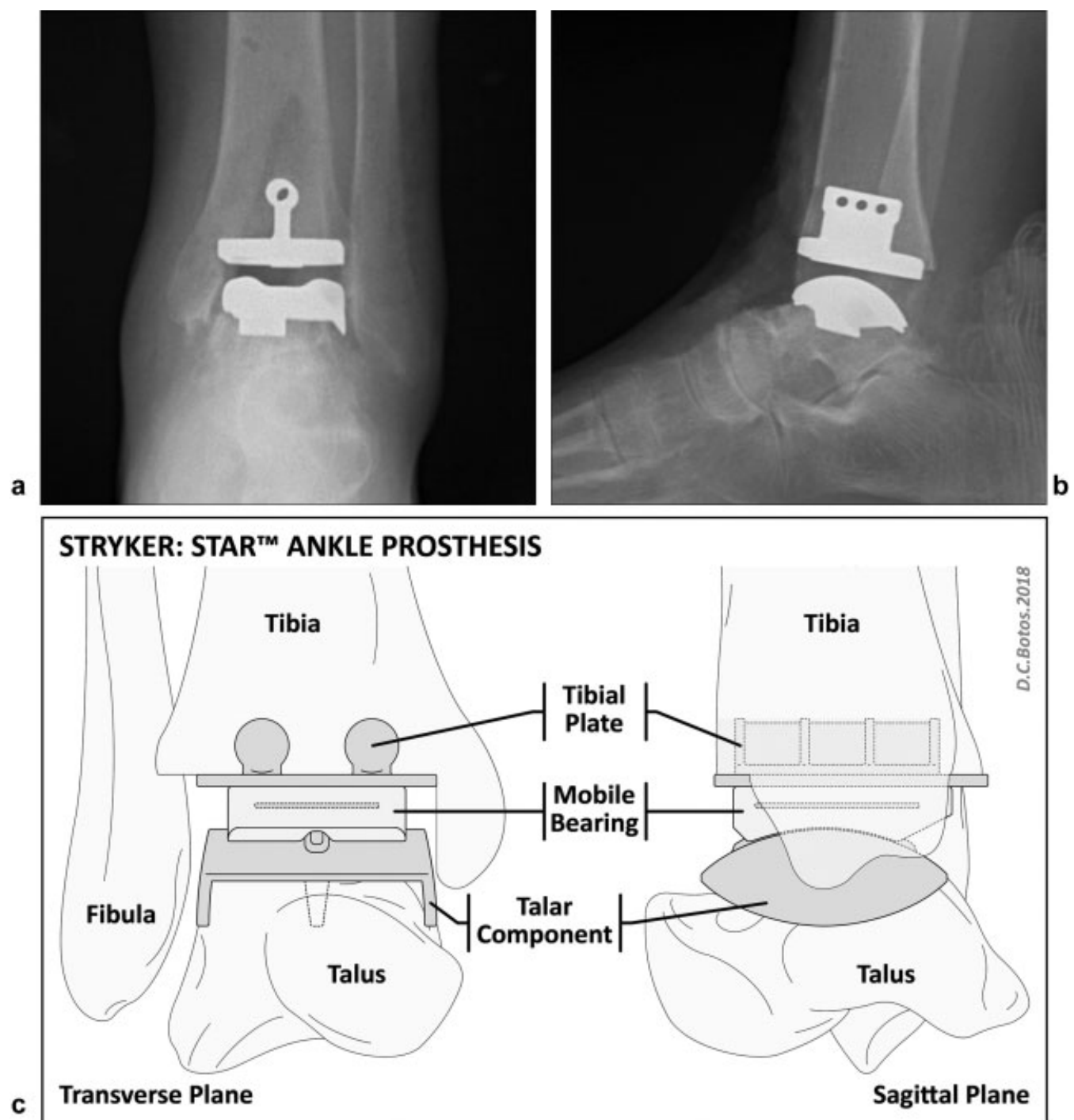

Fig. 2 Mobile-bearing total ankle arthroplasty (TAA). (a) Anteroposterior and (b) lateral radiographs of the ankle in a 71-year-old woman with a history of posttraumatic tibiotalar arthropathy who underwent cementless TAA of the ankle with the Salto Talaris device. The device consists of a tibial tray component, a talar dome prosthesis, and a radiolucent mobile spacer. The device is placed with an anterior approach that precludes syndesmotic disruption. (c) Line drawing of the STAR ankle prosthesis, a three-component mobile-bearing device that includes a tibial plate with two cylinders, a talar dome component with a keel, and an interposed mobile-bearing spacer.

replacement this is considered an off-label use by the FDA, reflecting the different regulatory pathways used to obtain clearance for marketing.

\section{Agility}

The Agility total ankle prosthesis (DePuy) (-Fig. 1), previously marketed as the Alvine Ankle, is a modular twocomponent ankle prosthesis composed of a titanium tibial tray with a locking semiconstrained PE tibial insert and a cobalt chromium talar component. ${ }^{16}$ Fusion of the distal tibiofibular syndesmosis is desired during implantation to stabilize the tibial component. As one of the earliest approved ankle prostheses, this line has some of the longest follow-up of any fixed-bearing total ankle replacement in the United States. Reported 5-year survival rate with reoperation as the end point is $54 \%$, and with arthroplasty failure as the end point is $80 \% .^{29,30}$ The Agility total ankle system design underwent modification in 2007. A broad-based talar component was redesigned to reduce subsidence of the tibial component, mixing and matching of component sizes was integrated to improve implant match with native anatomy, and the PE spacer was converted to frontloading to facilitate exchange (if needed). ${ }^{31}$ Despite these modifications, and despite being the most commonly performed implantation in the United States for $\sim 20$ years, the Agility product line is no longer commercially available, and current interest in this product line centers on revision techniques. ${ }^{32,33}$

\section{Salto Talaris}

The Salto Talaris Anatomic Ankle (Tornier) arthroplasty design (-Fig. 2a, b) is a derivative of the Salto (Tornier) ankle system modified for marketing within the United States. Specifically, whereas the Salto system (for the international market) is designed as a mobile-bearing prosthesis, 
the Salto Talaris was changed to a fixed-bearing prosthesis and subsequently received FDA clearance via the $510(\mathrm{k})$ premarket notification pathway after demonstrating substantial equivalence to legally marketed predicate devices. ${ }^{16}$ The tibial base and the talar components are manufactured from cobalt chromium alloy, with a PE insert. Although only approved for cemented use, the bone-contacting surfaces are coated with a titanium plasma spray to facilitate cementless fixation. The talar component is intended to mimic native talar anatomy, with asymmetric lateral larger than medial radii. The tibial component includes a short stem that projects into the distal tibia, and the PE component locks onto the tibial component. ${ }^{34}$

\section{Scandinavian Total Ankle Replacement}

The Scandinavian Total Ankle Replacement (Stryker), often marketed as the STAR ankle (-Fig. $\mathbf{2 c}$ ), is to date the only cementless prosthesis available in the United States, having undergone premarket approval via the investigational device exemption pathway. ${ }^{16}$ Initially a two-component prosthesis marketed in Europe, the STAR prosthesis has undergone multiple modifications throughout its clinical use. The most recent iteration of the STAR prosthesis is a threecomponent, mobile-bearing, cementless design including a trapezoidal tibial tray, a symmetrical partial cylinder talar component, and a PE spacer. The tibial component has two cylinders with ridges that allow for bony ingrowth, whereas the talar component has a fin that inserts into the talus. The metallic components' bone contact surfaces are coated with hydroxyapatite to facilitate bony ingrowth. ${ }^{35}$ The mobile component allows for rotation in addition to translation that may reduce junctional stress at the implant-bone interface. ${ }^{35,36}$

\section{Inbone I and II, Infinity, Invision}

The Inbone I (formerly known as the Topaz Total Ankle Replacement System) and Inbone II Total Ankle Systems are fixed-bearing two-component designs. The tibial and talar stem components are relatively long in comparison with other designs, and they are highly modular, allowing for customization based on patient anatomy. The intention of this design is to remove the mechanical load from the bearing components by the large stems. Although some authors have raised concern that transmission of forces by the long stem into the tibial metaphysis may contribute to loosening of the prosthesis, only limited or early-to-mid data are available to date on clinical and radiographic outcomes. ${ }^{37-41}$

The Infinity (Wright) total ankle system (-Fig. 3) was designed with the primary goal of limiting the amount of bone resection and soft tissue dissection necessary for implantation, and it has a significantly smaller profile relative to precursor devices. ${ }^{16}$ Limited early clinical and radiographic data indicate reoperation and revision rates that are similar or slightly favorable relative to prior systems, with longer term outcomes not currently available. ${ }^{42}$

The Invision (Wright) Total Ankle Revision System is a fixed-bearing system specifically designed for revision procedures. It is based on the Inbone platform with tibial trays that are compatible with previously indwelling Inbone talar stems. No specific literature regarding this system is currently available, beyond that published by the manufacturer.

Both the Inbone and Infinity ankle replacement systems can be implanted using an intramedullary referencing system or computed tomography (CT)-derived patient-specific plans and guides (PROPHECY, Wright Medical Technology) that is discussed subsequently in greater detail.

\section{Other Designs}

Additional recently FDA-approved devices include the Zimmer Trabecular Metal Total Ankle (Zimmer), the Vantage Total Ankle System (Exactech), the Cadence Total Ankle Replacement System (Integra LifeSciences), and the Hintermann Series H2 Total Ankle System (DT MedTech), all of which are two-part fixed-bearing designs, with subtle modifications relative to existing predicate devices.
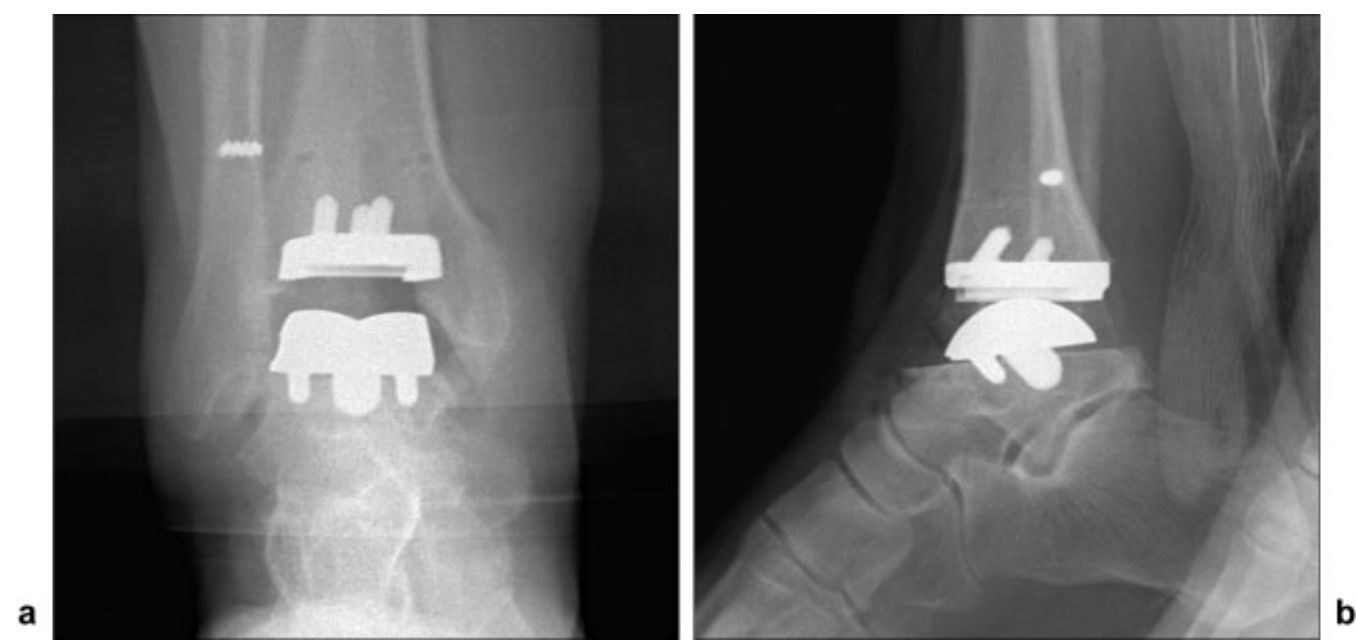

Fig. 3 Wright Infinity total ankle arthroplasty (TAA). (a) Anteroposterior and (b) lateral radiographs of the ankle in a 50-year-old woman with a history of posttraumatic ankle arthritis who has a mobile-bearing TAA with the Wright Infinity system. This device is smaller than prior designs and requires resection of less bone stock. 


\section{Indications}

The most common indication for TAA is for the treatment of advanced arthropathy resulting from end-stage primary osteoarthritis, posttraumatic arthrosis, or infectious or inflammatory arthritis (after the infection has cleared), in patients for whom preserved functional range of motion is desired. ${ }^{21,43-46}$ TAA is of particular interest for the treatment of patients with systemic diseases resulting in bilateral endstage osteoarthritis, such as patients with hemophilia, because a bilateral arthrodesis would result in a significant decrease of functional mobility. ${ }^{47}$

TAA is also indicated for patients who have had failed prior ankle surgery or in patients with prior hindfoot or midfoot fusion, for whom preserved functional range of motion is desired. TAA in combination with hindfoot fusion versus TAA in isolation demonstrated similar clinical outcomes. $^{48}$

The ideal candidate would be a middle-aged to older patient without significant comorbidities and a normal to low body mass index (BMI). To maximize the chances of a technically successful arthroplasty, the patient should have adequate tibial and talar bone stock, a stable and wellaligned hindfoot, adequate soft tissue support, and no lower extremity neurovascular impairment. ${ }^{49}$

\section{Contraindications}

Absolute and relative contraindications to TAA can be surmised by obversion of the ideal candidate just described. Absolute contraindications include (1) active soft tissue or bony infection; (2) neurovascular compromise such as neuroarthropathy (Charcot foot), severe sensorimotor dysfunction of the foot/ankle, and vascular inflow/outflow compromise; (3) compromised periarticular soft tissue restraints including laxity due to connective tissue disease or advanced scarring due to multiple prior surgeries or prior trauma; and (4) poor bone stock including severe osteoporosis or osteonecrosis. ${ }^{50}$

Previously considered an absolute contraindication, ${ }^{51}$ excessive hindfoot malalignment has been modified to a relative contraindication, provided additional realignment procedures are performed to address the deformity at the time of arthroplasty. ${ }^{52-54}$

\section{Considerations for Preoperative Imaging}

Several factors that can be identified on preoperative imaging may be helpful to the surgeon in matching appropriate TAA candidate patients with the optimal technique including the etiology of the arthropathy, the degree and type of ankle malalignment, the preoperative range of motion at the ankle joint, and the degree of periarticular fibrosis.

Postoperative range of motion is typically only improved by $\sim 5$ degrees relative to preoperative range of motion, indicating that a main factor influencing postoperative range of motion is in fact preoperative range of motion. ${ }^{55}$ Although no consensus method for measuring ankle range of motion exists, one such method was proposed by Coetzee et al. In this method, weightbearing lateral radiographs are obtained in neutral flexion, terminal dorsiflexion, and terminal plantar flexion, and lines are drawn from the posterior to anterior lip of the tibia and along the inferior aspect of the talus at the subtalar joint to determine tibiotalar angle and hence range of motion. This method has not been prospectively validated, but it is illustrative of the need for a measurement of tibiotalar range of motion that is reliable, accurate, and reproducible.

With increasing experience in the performance of TAA, there has also been a concomitant increase in the tendency to attempt treatment of more complex deformities. Although it was shown that preoperative hindfoot deformity is not an absolute contraindication to TAA, it is important to note that these deformities should be addressed at the time of prosthesis implantation or the life span of the implant could be compromised. ${ }^{54,56}$ Additionally, the nature of the ankle malalignment provides prognostic value; namely, patients with the valgus angle malalignment were shown to have superior postoperative range of motion compared with those with varus malalignment. ${ }^{57}$ As such, weightbearing preoperative radiographs should be obtained to assess for foot and ankle alignment, with attention paid to planus or cavus and varus or valgus deformities.

Identifying the etiology of the arthrosis needing TAA was also shown to demonstrate prognostic value. Lee et al demonstrated improved range of motion for patients with a primary ankle osteoarthritis relative to patients with a posttraumatic arthrosis. ${ }^{57}$ Although Bai et al demonstrated equivalent outcomes between the two groups, they also found a higher incidence of complication after TAA in the posttraumatic group. 58

With promising results of preoperative computer navigation and patient-specific instrumentation in total knee and hip arthroplasty, similar techniques have also been extended to TAA. First FDA approved in 2011, the PROPHECY (Wright) preoperative navigation alignment guide is to date the only such system currently in use, and it is compatible with both the Inbone (Wright) and Infinity (Wright) ankle systems. The guides are designed from patient-specific CTs and subsequently manufactured for single use. The guides are intended to serve as an alternative to traditional alignment instrumentation and therefore reduce the number of steps required during surgery. Early clinical evidence suggests the use of such a system results in reliable, repeatable implant placement, improved implant alignment, and decreased procedural time, although further data are needed regarding clinical implications. ${ }^{59-61}$

\section{Complications}

TAA has been more prone to developing complications and has had higher revision rates than total knee or hip arthroplasty, which may in part be responsible for the slower acceptance of TAA in the treatment of end-stage ankle arthropathy. A recent pooled data analysis by Lawton et al comparing the outcomes of TAA with ankle arthrodesis 
reported an overall complication rate of $20 \%$ with a revision rate of $8 \%$ in six studies that met the authors' inclusion criteria, totaling 2,239 ankles. $^{62}$ For comparison, the reported survivorship rate for total knee arthroplasty is generally $>95 \%$ at 10 years and $>85 \%$ for total hip arthroplasty at 10 years. ${ }^{63,64}$ The most common reason for implant failure is aseptic loosening, followed by persistent pain and periprosthetic infection. ${ }^{65}$ There has been high variability in reported survivorship of TAAs. A meta-analysis by Gougoulias et al involving 1,105 devices from 13 studies reported a $10 \%$ failure rate at 5 years, with failure defined as implant revision or explantation followed by arthrodesis. ${ }^{66}$ Barg et al studied the results on 722 TAAs in 684 patients who received the HINTEGRA TAA and found survivorship at 5 years was $94 \%$ and was $84 \%$ at 10 years. ${ }^{67}$ The types of complications and reporting of complications varies from region to region, which could be related to the type of devices used and to the technical experience of the operating surgeon. ${ }^{68,69}$

Incomplete understanding of abnormal biomechanics, particularly in the design of early-generation TAAs, may predispose TAA to abnormal stresses that can lead to complications, such as aseptic loosening or osteolysis. However, progressive improvements in the design of these devices have taken the normal biomechanics of the ankle into consideration. Initial designs were constrained in movement, operating roughly as hinge joints that allowed ankle flexion and extension. ${ }^{10}$ However, there is greater awareness among foot and ankle surgeons about rotation and sliding motions that are critical in allowing normal tibiotalar motion. ${ }^{70-72}$ Incongruent tibial and talar articular surfaces increased edge loading (abnormal contact between the PE spacer and a metallic edge) and resulted in greater PE spacer wear. ${ }^{73,74}$ In addition, initial surgeries for TAA may have attempted to correct articular surface abnormalities without addressing underlying malalignment, such as hindfoot valgus or varus deformities, or insufficiency of the surrounding soft tissue restraints.

Newer devices attempt to maintain physiologic transfer of forces between the distal tibia and talus through the arthroplasty without inducing excessive edge loading that can lead to device failure. Although first-generation devices were cemented to achieve greater postoperative implant stability, it was recognized that shear forces were concentrated at the cement-bone interface, and cement requires a greater amount of bone resection. As a result, cemented prostheses developed a high rate of aseptic loosening and osteolysis. ${ }^{74}$ Thus, the metallic surfaces of newer devices are porous bead coated and coated with hydroxyapatite, and the devices are placed press fit to encourage greater osteointegration. Finally, many of the earlier designs resected more native bone, particularly in the distal tibial metaphysis, that prevented the normal transfer of forces from the native tibia to the tibial prosthesis, and long stem tibial components used frequently in early designs may also have led to increased stress in the distal tibial metaphysis. Many newer devices are placed by resecting as little native bone as possible. This not only improves load transfer within the ankle but also preserves bone stock in case surgical revision is required.
Several complications are seen with TAA that can be divided into several categories. Some authors list complications based on frequency of occurrence. Work by Lee et al of 262 TAAs in 260 patients demonstrated that $62 \%$ of these devices showed radiographic evidence of complication. Periprosthetic lucency was seen in $34 \%$ of cases, hardware subsidence was seen in $24 \%$, peri-hardware fracture was noted in $11 \%$, syndesmotic screw loosening was seen in $10 \%$, and screw fracture was seen in $6.5 \%$ of cases. ${ }^{75}$ Glazebrook et al categorized complications into high risk, intermediate risk, or low risk for the development of implant failure. ${ }^{76}$ It may be helpful for clinicians evaluating radiologic studies to use a classification scheme that divides complications temporally into intraoperative, early postoperative, and late postoperative categories. Intraoperative complications include neurovascular bundle injury, tendon injury, excessive resection of bone, and medial malleolar fracture. Early postoperative complications include medial malleolar stress fracture, distal fibular fracture, distal tibial fracture, delayed wound healing, and infection. Finally, late postoperative complications involve periprosthetic fracture, aseptic loosening, subsidence, expansile osteolysis, impingement, PE spacer wear and migration, syndesmotic nonunion, heterotopic ossification, osteoarthritis in neighboring joints, and chronic regional pain syndrome. ${ }^{77}$

\section{Aseptic Loosening}

Aseptic loosening is the most common complication found in patients with TAA and the most common indication for prosthetic revision. Approximately $40 \%$ of revised TAAs are due to aseptic loosening. ${ }^{65,69}$ Not all patients who develop radiographic signs of aseptic loosening are symptomatic, although the radiographic development of excessive periprosthetic lucency could precede the development of symptoms. ${ }^{75,78}$ The etiology of periprosthetic loosening is not well understood and likely multifactorial. This may include micro-motion at the prosthesis-bone interface due to shear and rotational forces, localized tissue necrosis with development of a reparative membrane, shedding of PE particles that induces a cell-mediated reaction and releases matrix metalloproteinases that inhibit bone ingrowth, and the development of fluid between the prosthesis and the bone.

Other factors, such as genetics, activity level, specific model used, and body weight (BMI $>30$ ), were also associated with the development of aseptic loosening. ${ }^{79}$ Radiographically, loosening is determined when there is lucency around the prosthetic component at the prosthesis-bone interface that measures $>2 \mathrm{~mm}$ in width (-Fig. 4). The management of symptomatic aseptic loosening includes nonsurgical and surgical treatment options. It may respond to oral nonsteroidal anti-inflammatory drugs, activity modification or immobilization, and targeted local anesthetic/ steroid injection if there is concern for synovitis. For patients failing conservative measures, surgical options such as revision arthroplasty, arthrodesis of the tibiotalar or tibiotalocalcaneal joints with bone block grafting, and even belowknee amputation can be considered. ${ }^{80}$ 


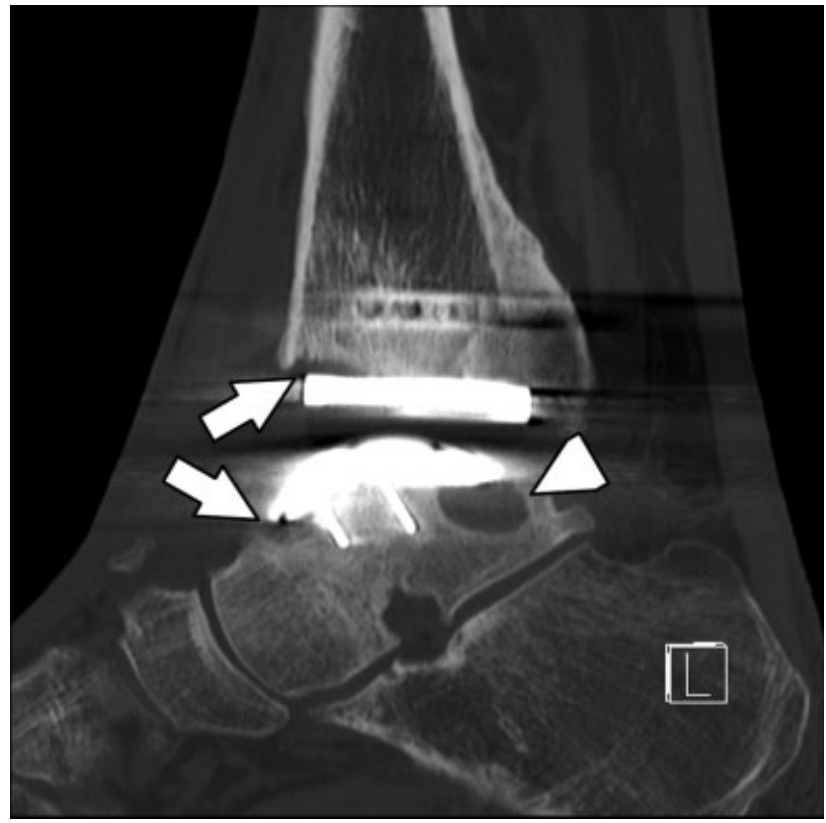

Fig. 4 Aseptic loosening. Sagittal reformatted computed tomography image in a 54-year-old man who had posttraumatic ankle arthropathy and underwent total ankle arthroplasty (TAA) with a Salto Talaris device. There are areas of periprosthetic lucency $>2 \mathrm{~mm}$ in thickness along the anterior tibial and talar bone-prosthetic interfaces (arrows). Along the posterior margin of the talar prosthesis is a developing periprosthetic cyst formation as well (arrowhead).

\section{Expansile Osteolysis}

Expansile osteolysis, also known as ballooning osteolysis or periprosthetic cysts, has been seen in up to $15 \%$ of TAAs and may lead to device instability, periprosthetic fractures, and talar component collapse. ${ }^{81}$ It represents collections of $\mathrm{T}$ cell-mediated immune response to the prosthesis that releases cytokines and induces osteoclast function. This results in bone destruction associated with areas of necrotic tissue. Like aseptic loosening, the precise cause of this complication is unknown and likely related to several factors. It was proposed that shed PE particles engulfed by macrophages induce the inflammatory cascade. However, a study by van Wijngaarden et al that performed histologic analysis of 22 cases of periprosthetic osteolytic cysts in patients with TAAs did not find an association between concentration of PE particles and time to surgical revision. The authors concluded that PE particles may not be solely responsible for the development of expansile osteolysis. ${ }^{82}$ Additionally, the hydroxyapatite coating may also be associated with cyst development. ${ }^{83}$

Radiographically, these periprosthetic cysts are rounded areas of periprosthetic lucency, often with thinning of the overlying cortex. They may have a thin rim of peripheral sclerosis, indicating an indolent rate of growth (-Fig. 5). Because the development of expansile osteolysis erodes bone stock and may result in implant failure, these cysts are often followed on serial radiographs to determine their rate of enlargement. Additionally, CT is frequently performed to better characterize these lesions and to detect lesions that may be radiographically occult. Several treatment options are available if the periprosthetic cyst is considered symptomatic. In most instances, curettage and bone graft packing of the cysts, along with exchange of the PE spacer, have been performed. In more advanced cases, either implant revision or removal followed by arthrodesis may be required. ${ }^{81}$

\section{Subsidence and Component Migration}

Along with aseptic loosening, subsidence represents the most common postoperative complication associated with
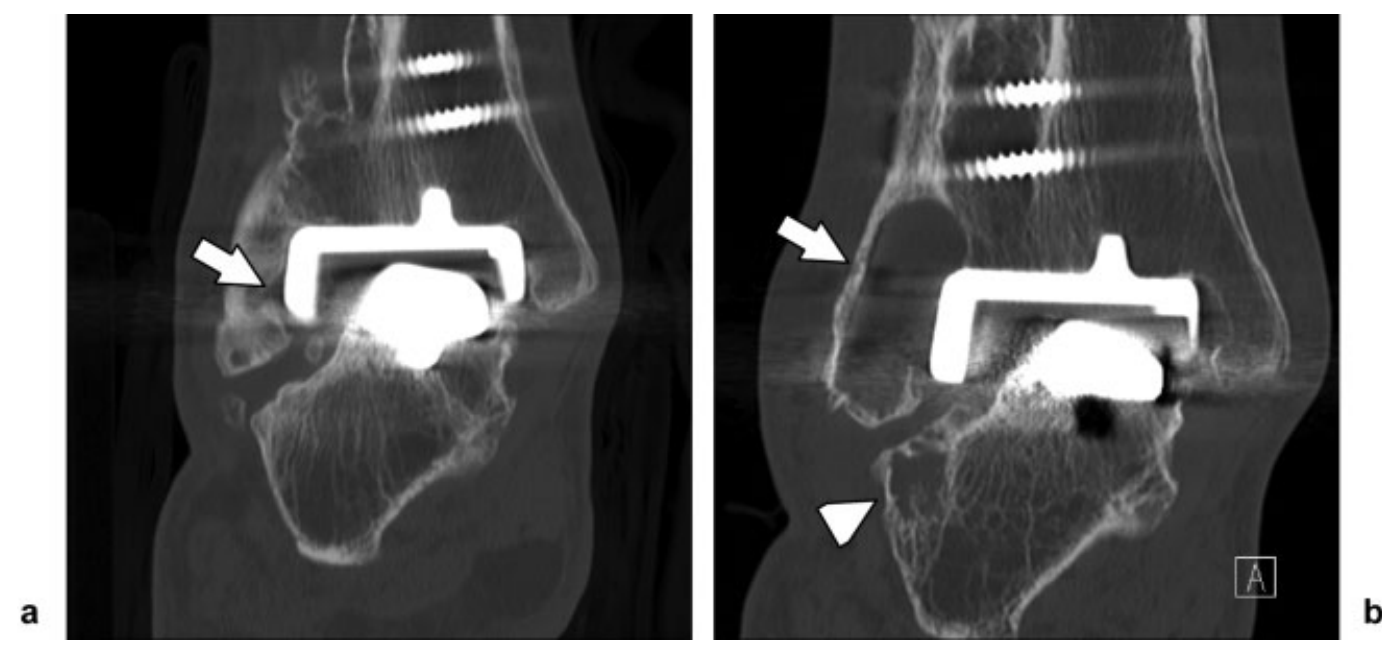

Fig. 5 Expansile osteolysis. (a) Initial coronal computed tomography (CT) reformatted image from 2009 in a 68-year-old female patient who has total ankle arthroplasty (TAA) with the Agility prosthetic system does not show expansile osteolysis. There is suggestion of hindfoot valgus and mild lucency along the lateral tibiofibular tray within the fibula (arrow) that could represent early aseptic loosening. (b) Subsequent CT coronal reformatted image of the same ankle in 2012 now shows an area of expansile osteolysis in the lateral malleolus (arrow). As in this case, many of these lesions associated with particle disease have a thin rim of peripheral sclerosis, suggesting a more indolent process than other causes of osteolysis such as infection. In addition, there is greater hindfoot valgus with narrowing of the subfibular distance and a new lateral talar body subcortical cyst formation (arrowhead) that could be related to subfibular impingement. 
a
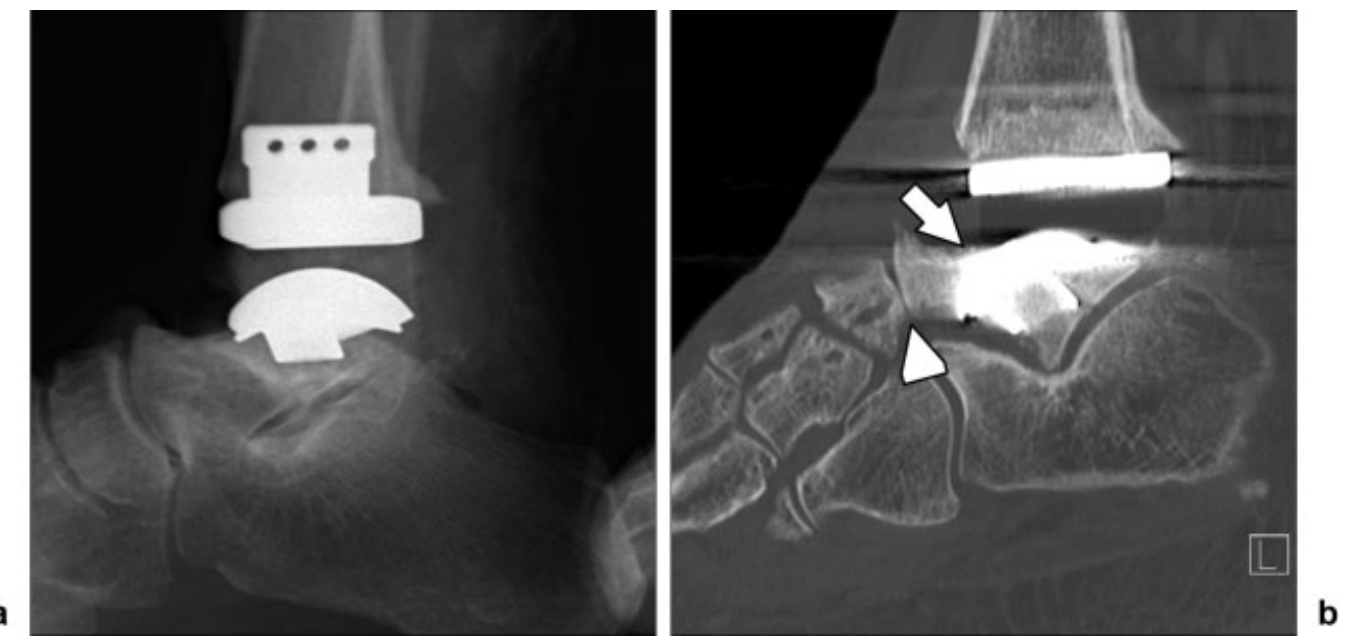

Fig. 6 Subsidence. A 64-year-old female patient who has total ankle arthroplasty with the Salto Talaris system presented with persistent ankle pain. (a) Initial lateral intraoperative fluoroscopic image of the same ankle demonstrates the normal position of the talar dome component. (b) Sagittal computed tomography (CT) reformatted image of the ankle performed 15 months later shows depression of the talar dome component. The anterior margin of the talar component is $10 \mathrm{~mm}$ inferior to the dorsal margin of the talar neck (arrow), and the apex of the talar dome is at the same height as the dorsal talar neck. The maximal amount of inferior migration before subsidence is diagnosed is $5 \mathrm{~mm}$. There is also developing joint narrowing and osteoarthritis of the talonavicular joint (arrowhead) that was not seen on the initial fluoroscopic image and a preoperative CT (not shown).

TAA failure, and subsidence was reported in nearly $11 \%$ of failed TAAs. ${ }^{76}$ It reflects loosening and irregular distribution of force across the prosthesis that may result in further osseous erosion and component malalignment, osteonecrosis, or talomalleolar impingement. ${ }^{84}$ Subsidence in the tibia has become much less common than in the talus after the widespread use of cementless tibial component fixation. ${ }^{85}$ Soon after surgery there may be physiologic settling of the talar component. However, this should be very mild and not continue to progress for $>6$ months. Radiographically, subsidence may be determined by $>5-\mathrm{mm}$ depression, most commonly of the talar component, possibly associated with angular deformities $>5$ degrees $\left(-\right.$ Fig. 6) ${ }^{29}$ Several treatment options have been performed for subsidence including revision TAA and ankle or tibiotalocalcaneal arthrodesis. ${ }^{86}$

\section{Infection and Delayed Wound Healing}

Infection occurs in up to $10 \%$ of patients with TAAs and includes superficial wound infections that may lead to delayed wound closure and deeper periprosthetic infections. Infections are categorized by the time frame following surgery as either acute (within 6 weeks of surgery) or late ( $>6$ weeks following surgery) (-Fig. 7). Radiography may not demonstrate an abnormality in the setting of an acute infection. Initial evaluation is more clinical and should include serum erythrocyte sedimentation rate and C-reactive protein, which are commonly elevated markers of inflammation/infection. However, as the infection progresses there may be soft tissue swelling, periosteal reaction, and osteolysis.

CT or magnetic resonance imaging (MRI) using metal artifact reduction techniques may be helpful to detect these findings earlier, and MRI may detect periprosthetic bone marrow edema or replacement if the clinical and radiographic findings cannot clearly diagnose or exclude infec- tion. Nuclear medicine studies, such as three-phase bone scan, may indicate areas of rapid bone turnover that can be seen with active infections. Additionally, indium-111-

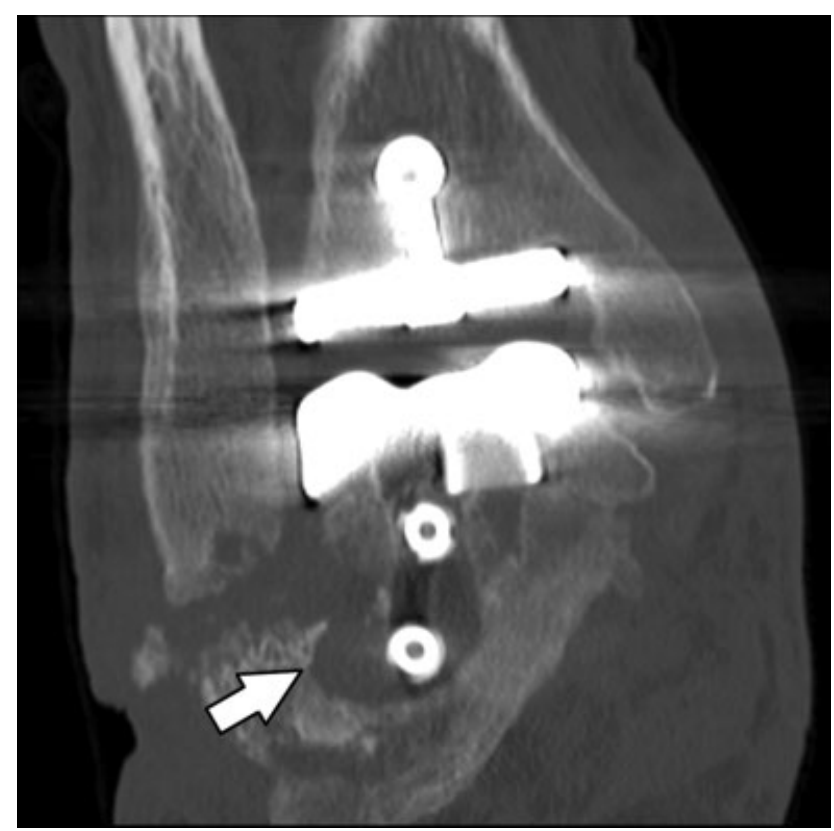

Fig. 7 Periprosthetic infection. A 56-year-old male patient underwent Salto Talaris total ankle arthroplasty and developed pain and swelling within 6 months of the initial surgery. Laboratory studies showed elevated C-reactive protein. Coronal computed tomography reformatted image of the ankle shows significant osteolysis around the talar component and screws bridging the subtalar joint (arrow). The osteolysis extends to the lateral calcaneal body. Unlike many cases of aseptic expansile osteolysis, there is no peripheral sclerosis surrounding the region of osteolysis, which reflects a more aggressive process. The treating orthopaedic surgeon removed the infected hardware and ultimately performed arthrodesis once the infection was cured. 
labeled leukocyte scans in combination with technetium$99 \mathrm{~m}$ (Tc-99m) sulfur colloid imaging of the bone marrow have been performed to add specificity to the diagnosis. Finally, ultrasound (US) may be helpful in detecting and aspirating joint effusions and periprosthetic collections that may help to isolate a causative organism. Superficial infections may be treated with antibiotics and wound debridement, whereas deeper infections may require debridement, device component exchange, and longer duration of antibiotics. ${ }^{87}$

\section{Periprosthetic Fracture}

Although it is the most common intraoperative complication during TAA, periprosthetic fracture is relatively uncommon and has reportedly occurred in $\sim 4 \%$ of cases ${ }^{88}$ Fractures can either be intraoperative or postoperative. When intraoperative they are likely related to technical factors such as level of surgical experience, component overstuffing (placement of prosthetic components that are larger than the osteotomy bed), or component malpositioning. In contrast, postoperative fractures may be either posttraumatic or stress related. Excessive bone resection, component overstuffing, or malposition may contribute to posttraumatic postoperative fractures. ${ }^{85}$ Stress fractures are most common in the medial malleolus and may be due to patient noncompliance with weightbearing instructions. In addition, varus malpositioning of the tibial implant during surgery may also contribute to abnormal stress in the medial malleolus (-Fig. 8). They can also be associated with osteoporosis and excessive distal tibial bone resection or multiple pin stabilization of the distal tibia during the procedure. Most periprosthetic

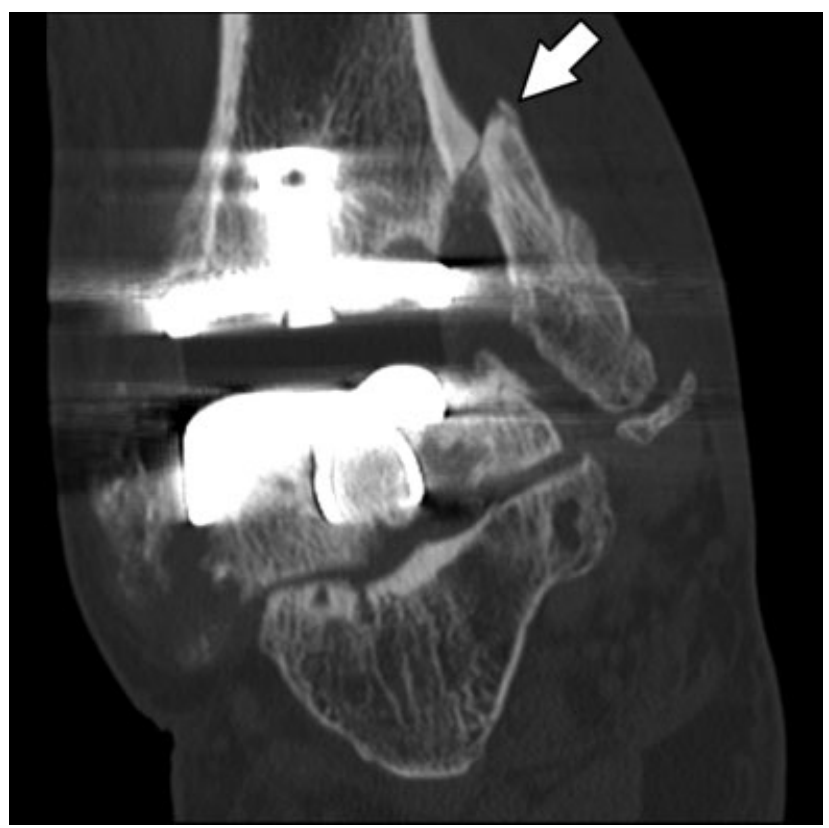

Fig. 8 Periprosthetic fracture. Coronal computed tomography reformatted image of the ankle in a 63-year-old female patient who has total ankle arthroplasty with the Salto Talaris system demonstrates an obliquely oriented, medially displaced fracture through the base of the medial malleolus (arrow) following low-impact trauma. fractures can be managed with immobilization and limited weightbearing unless there is fracture displacement or instability. ${ }^{88}$

\section{Heterotopic Ossification and Osseous Spurring}

Heterotopic ossification is commonly seen following TAA, reported in $>90 \%$ of patients after 3 years following surgery. ${ }^{89,90}$ It can lead to symptomatic ankle impingement. Few factors are known to correlate with its development; however, component undersizing relative to the osteotomy bed may be associated. Radiographically, it occurs most commonly posteriorly but can be seen anywhere around the joint (-Fig. 9). A grading system modified from the Brooker system of heterotopic ossification in the hip was proposed with grade 0 representing no heterotopic ossification; grade 1, a small island of isolated ossification; grade 2 , multiple foci of ossification that are not confluent; and grade 3, confluent, bridging ossification..$^{90}$ Debridement can be performed if the focus of heterotopic ossification is considered symptomatic. However, occasionally resection of osteophytes can lead to instability. ${ }^{85}$

\section{PE Spacer Displacement or Fracture}

Mobile-bearing TAAs are designed to increase range of ankle motion and to reduce the load transfer to the prosthesisbone interface. However, this results in relative PE spacer instability and the possibility of displacement. Additionally, there are reports of spacer wearing or even fracture that is likely due to abnormal contact forces and edge loading (-Fig. 10). Metal markers are embedded in the PE spacers

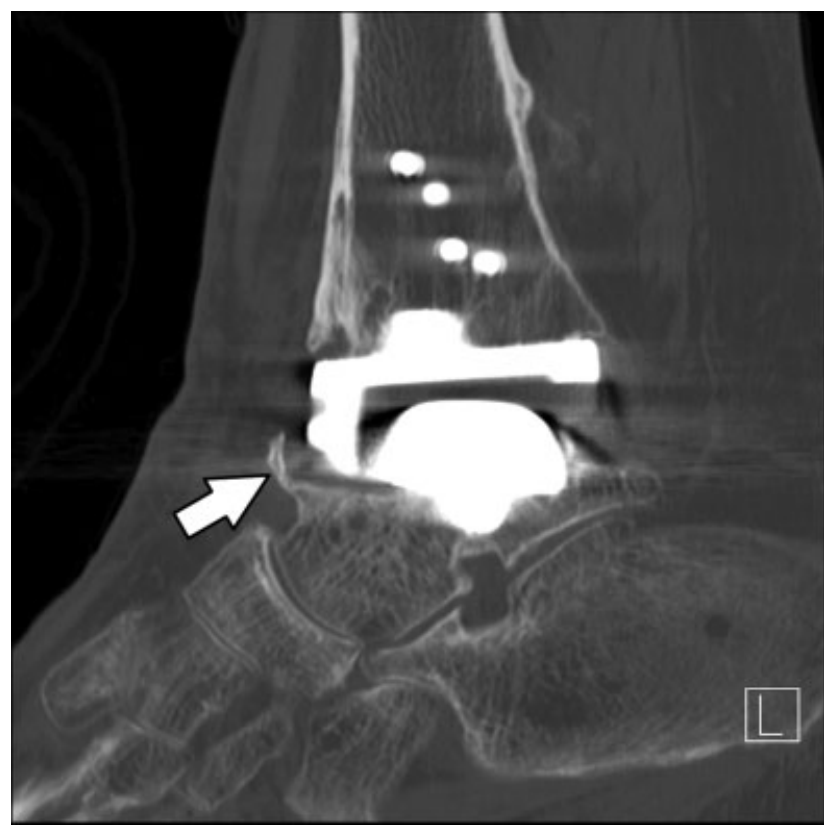

Fig. 9 Heterotopic ossification. Sagittal computed tomography reformatted image of the ankle in a 76-year-old female patient who has an Agility total ankle arthroplasty (TAA). There is curvilinear ossification arising from the anterior margin of the talar component (arrow). Heterotopic ossification most commonly occurs posteriorly and has reportedly been observed in most TAAs. 

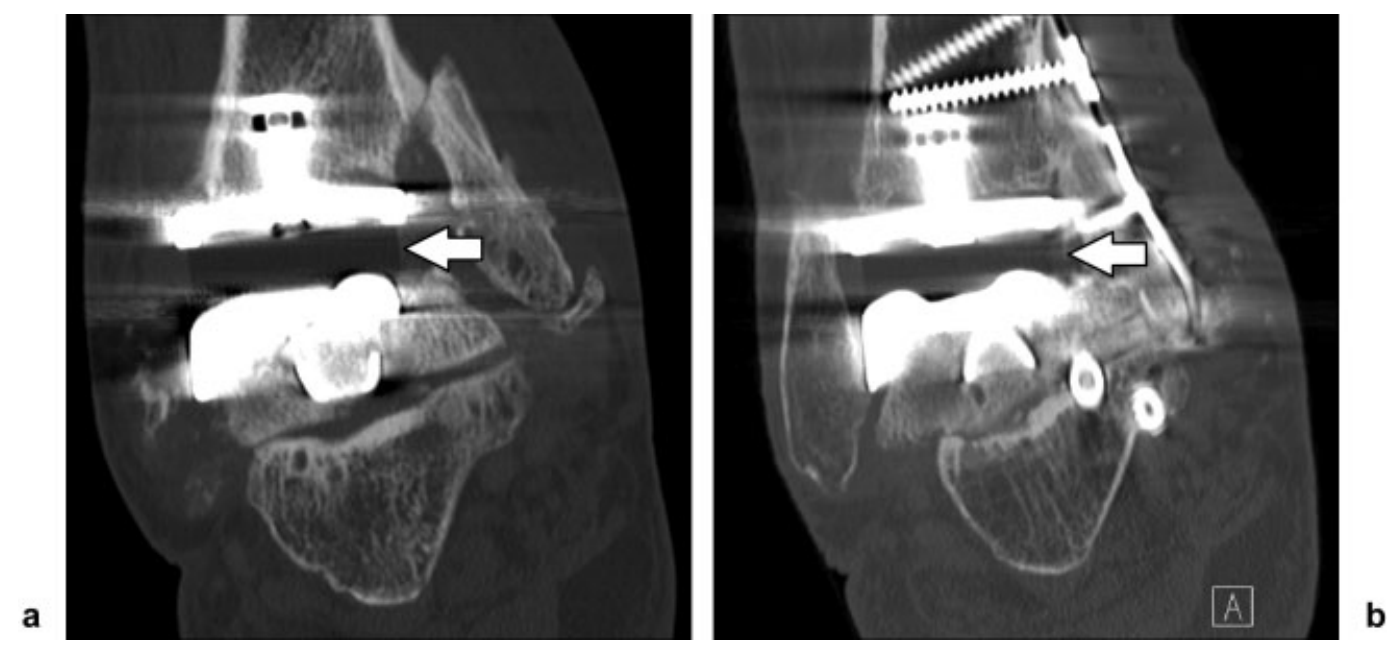

Fig. 10 Polyethylene spacer wearing. A 64-year-old female patient who has total ankle arthroplasty with the Salto Talaris system and presented with medial ankle pain. This is the same patient who initially presented with medial malleolar fracture in $\boldsymbol{- F i g . ~ 8}$. (a) Initial coronal reformatted computed tomography image of the ankle shows a uniform thickness of the radiolucent spacer measuring $6.5 \mathrm{~mm}$ (arrow). (b) Subsequent coronal reformatted image of the ankle 1 year after medial malleolar fracture fixation shows mild hindfoot varus and subtle thinning of the medial portion of the spacer (arrow), now measuring $4.5 \mathrm{~mm}$, which suggests edge loading medially.

of many models, and radiographically, displacement or extrusion is seen as abnormal movement of the radioopaque markers. Fracture of the spacer may be difficult to detect radiographically unless there is displacement of the markers. CT may be the best imaging modality to assess for PE spacer displacement or fracture because the spacer is well seen as a lucent structure usually located between the tibial and talar prosthetic components. PE spacer exchange can be performed if the spacer is worn or fractured. However, the prosthetic component alignment and status of the stabilizing ligaments should be assessed to determine whether there are abnormal contact pressures within the joint that may predispose the device to repeated failure. ${ }^{91}$

\section{Osteoarthritis of Neighboring Joints}

Among the proposed benefits of TAA compared with ankle arthrodesis is decreased stress on neighboring joints that may decrease rates of hindfoot arthropathy in the subtalar and talonavicular joints. However, Knecht et al reported their experience with 117 ankles that underwent TAA with the Agility Total Ankle prosthesis and found that 19\% of patients developed progressive subtalar osteoarthritis, and $15 \%$ had progressive talonavicular osteoarthritis ( - Fig. 6b). ${ }^{29}$ More recently, Kerkhoff et al reported development of subtalar and talonavicular osteoarthritis in $9 \%$ and $11 \%$, respectively, at 10-year follow-up of 134 TAAs using the STAR system. ${ }^{92}$ However, the reported frequency of subtalar and talonavicular osteoarthritis following ankle arthrodesis varies widely but is generally higher ranging between $10 \%$ and $60 \% .{ }^{93-95}$ Follow-up for the patients with ankle arthrodesis in these studies was generally longer than that for TAA, which could partially account for the differences. Therefore, it seems that TAA may trend toward lower rates of subtalar and talonavicular osteoarthritis, although it does not completely eliminate this complication.

\section{Imaging Strategy}

Several imaging modalities, including radiography, fluoroscopy, CT, MRI, and nuclear medicine studies such as bone scintigraphy using planar imaging and single-photon emission computed tomography (SPECT), as well as combination indium-111-labeled leukocyte/sulfur colloid bone marrow scintigraphy studies, have been used to assess total ankle arthroplasties. Of these, the mainstay is serial radiography. ${ }^{28,77}$ Studies are helpful to detect subtle abnormalities such as subsidence, early osteolysis, and angular deformities that may indicate aseptic loosening or possibly infection.

No consensus time frame for obtaining follow-up imaging has been established. Barg et al performed imaging immediately postoperatively, at 6 weeks, 3 months, 6 months, 1 year, and annually thereafter. ${ }^{96}$ Lee et al performed radiography immediately postoperatively, at 3 months, 6 months, 1 year, and then annually. ${ }^{97}$ Immediate postoperative anteroposterior (AP) and lateral radiographs are helpful in determining whether the bones and orthopaedic implants are in expected alignment. They are also adequate in establishing a baseline alignment for future assessments. However, they are performed without weightbearing, and attention to proper positioning will ensure these radiographs are useful as a comparison study for future examinations. ${ }^{97}$ Subsequent studies are performed with AP and lateral weightbearing technique depending on patient tolerance, and some institutions include lateral non-weightbearing maximally dorsiflexed and plantarflexed images to assess the range of motion. ${ }^{98}$ The subsequent studies are used to evaluate for signs of osteointegration, determine osseous and prosthetic component alignment, and detect developing heterotopic ossification, in addition to evaluating range of motion.

Abnormal movement of the orthopaedic hardware or periprosthetic lucency may indicate device loosening and 
may be subtle on radiography. As a result, the imager must have a clear understanding of the normal imaging appearance of a particular device. ${ }^{77}$ Device movement can be assessed by either linear or angular measurements, and an angular change of 5 degrees, $>5 \mathrm{~mm}$ of component migration, or $>2 \mathrm{~mm}$ of lucency surrounding the hardware component at the bone-metal interface are all criteria used to diagnose loosening (-Fig. 11). ${ }^{77,99}$ On immediate or early postoperative radiographic studies, there may be some expected periprosthetic lucency $>2 \mathrm{~mm}$ in width due to orthopaedic technique that may require resection of some bone to allow appropriate device implantation. These areas must be reassessed on follow-up imaging and should even- tually resolve with osteointegration. The rate of component migration can also be helpful because rapid changes in position are more commonly associated with infection. ${ }^{100}$

Zonal systems used radiographically have been described to help localize abnormalities. One commonly used system divides the tibial component on the AP image into five or six equal-size segments and numbers the segments from 1 to 5 (or 6) labeled medial to lateral. The tibial component on the lateral radiograph is divided into three equal-size segments labeled A, B, and C from anterior to posterior (- Fig. 12). ${ }^{99} \mathrm{~A}$ second 10-zone system was described by Besse et al, particularly to localize areas of expansile osteolysis. On the AP radiograph there are five zones that include the lateral tibia,
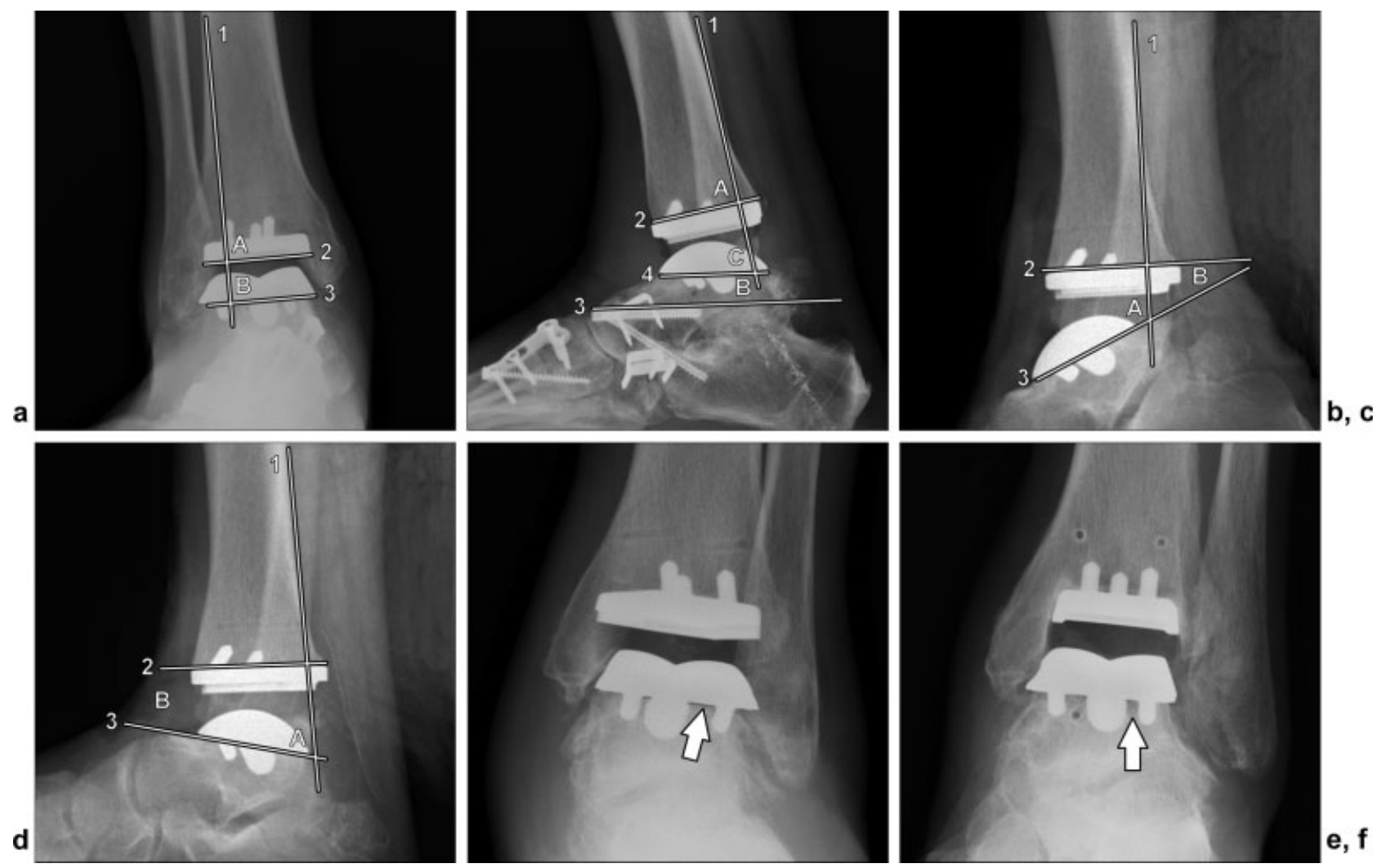

Fig. 11 Normal radiographic appearances of total ankle arthroplasty (TAA). (a) Anteroposterior (AP) radiograph of the ankle following TAA shows the normal relationship of the prosthetic components with the distal tibial and talus. The tibial component angle (angle $A$ ) is formed between the tibial long axis taken parallel to the lateral tibial diaphyseal cortex (line 1) and the surface of the tibial plate (line 2 ), and it measures 89 degrees \pm 3 degrees. The AP talar component angle (angle B) is formed by the tibial long axis (line 1 ) and a line tangent to the talar prosthesis at its bony interface. This should also measure $\sim 90$ degrees. (b) Lateral radiograph of the ankle also demonstrates the normal relationships of the tibial and talar prostheses and bones. The tibial long axis (line 1) is drawn along the posterior tibial diaphyseal cortex. The lateral tibial component angle (angle A) is formed by the long axis of the tibia and a line drawn tangent to the tibial tray at its osseous interface (line 2). Similar to the AP tibial component angle, this should also be $\sim 90$ degrees. The talar component angle (angle B) is formed by drawing a line connecting the anterior/superior margin of the talar head and the posterior/inferior margin of the talar body (line 3 ) and another line tangent to the flat talar prosthetic component at its osseous interface (line 4 ). This should measure $\leq 10$ degrees. Angle $\mathrm{C}$ is formed by the tibial long axis (line 1 ) and the flat talar component surface (line 4) and used to determine the range of motion during plantar flexion and dorsiflexion. Lateral fluoroscopic intraoperative images of the ankle following arthroplasty in full plantarflexion (c) and dorsiflexion (d) demonstrate two ways to determine angular movement. One could either determine angle A, which represents the angle between the tibial long axis (line 1) and the flat surface of the talar prosthesis (line 3), or angle B, which represents the angle formed by a line tangent to the flat surface of the tibial component (line 2 ) and the flat surface of the talar component (line 3 ). Using angle B, normal maximal dorsiflexion is generally $\sim 5$ degrees; normal maximal plantarflexion is $\sim 20$ degrees. Angle A can be estimated and is roughly 90 degrees. (e) AP radiograph of an INFINITY TAA system soon after surgery demonstrates expected periprosthetic lucency at the prosthesis-bone interface (arrow). This is smooth, measures $<2 \mathrm{~mm}$, and is commonly seen soon after TAA as part of the surgical technique. It should not be mistaken for aseptic loosening. (f) Repeat AP radiograph of the ankle demonstrates signs of osteointegration. Bone extends to the margin of the talar prosthesis and the previously noted periprosthetic lucency is no longer visible (arrow). 

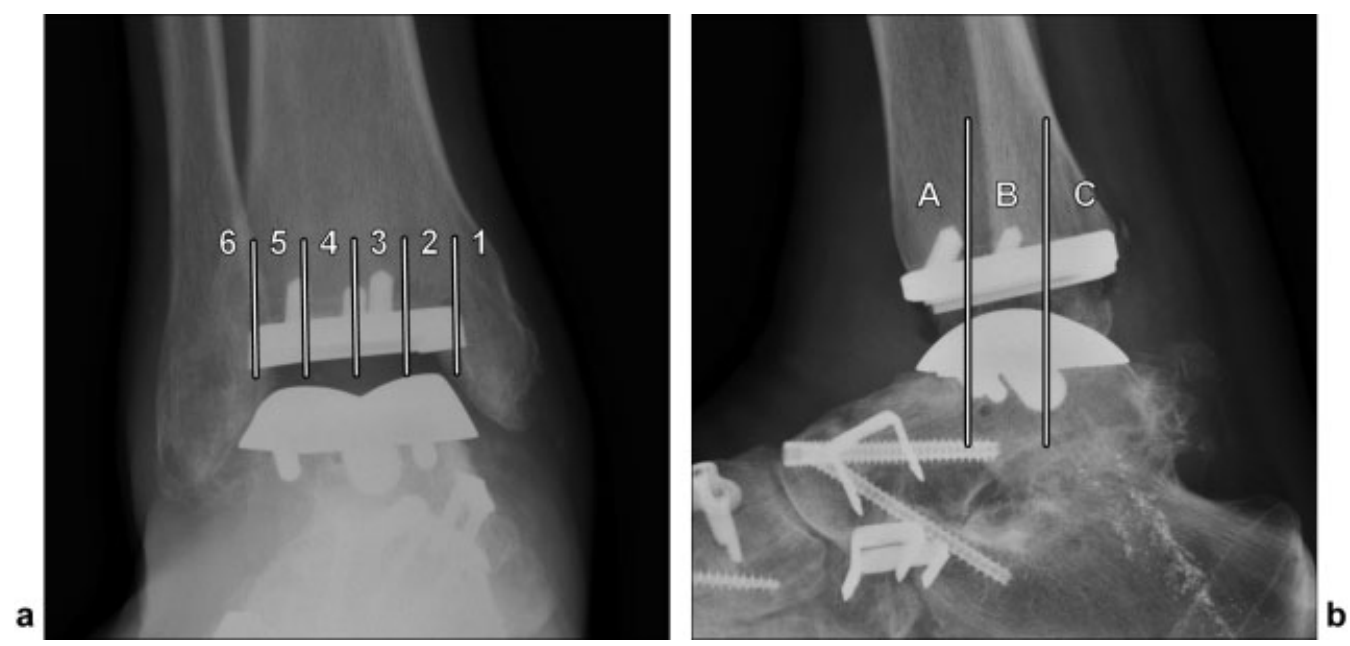

Fig. 12 Pyevich zonal system for characterizing aseptic loosening. This system has been used to standardize reporting of areas of periprosthetic loosening. (a) On the anteroposterior radiograph of the ankle, the articular surfaces of the ankle joint are segmented into five or six regions that are consecutively numbered from 1 to 5 (or 6 ) from medial to lateral. (b) On the lateral radiograph, the articular surfaces are divided into three equal-size regions labeled $\mathrm{A}, \mathrm{B}$, and $\mathrm{C}$ from anterior to posterior.

medial tibia, lateral malleolus, medial malleolus, and area under the talar implant at the metal-bone interface. On the lateral radiograph there are also five zones: the anterior tibia, posterior tibia, posterior implant-bone interface, anterior implant-bone interface, and the talar head/neck junction (-Fig. 13). ${ }^{101}$

CT has excellent spatial resolution and better contrast resolution than radiography, and it helps characterize bones for fracture, focal osteolysis, and periosteal reactions. However, CT of metallic devices is prone to photon starvation and beam-hardening artifacts that may make it difficult to assess the prosthesis-bone interface. In addition, most subtle osseous and prosthetic malalignments can be detected radiographically. Thus $\mathrm{CT}$ is most often used to confirm suspected areas of periprosthetic expansile osteolysis seen on radiography or to further assess these lesions and determine the degree of bone stock loss (- Fig. 14). ${ }^{102-104}$ Several techniques have been used successfully to reduce the degree of metal-related artifact and improve prosthetic assessment. These include making sure the long axis of the tibial prosthesis is oriented along the long axis of the CT table, ${ }^{105}$ using thinner section imaging, increasing $\mathrm{kVp}$ or possibly $\mathrm{mAs}$, viewing the implant in wider windows, and using a softer reconstruction kernel, such as the soft tissue algorithm. Newer techniques, such as obtaining monoenergetic CT images via dual-energy computed tomography or iterative metal artifact reduction, have also been performed with excellent results when available. ${ }^{106,107}$
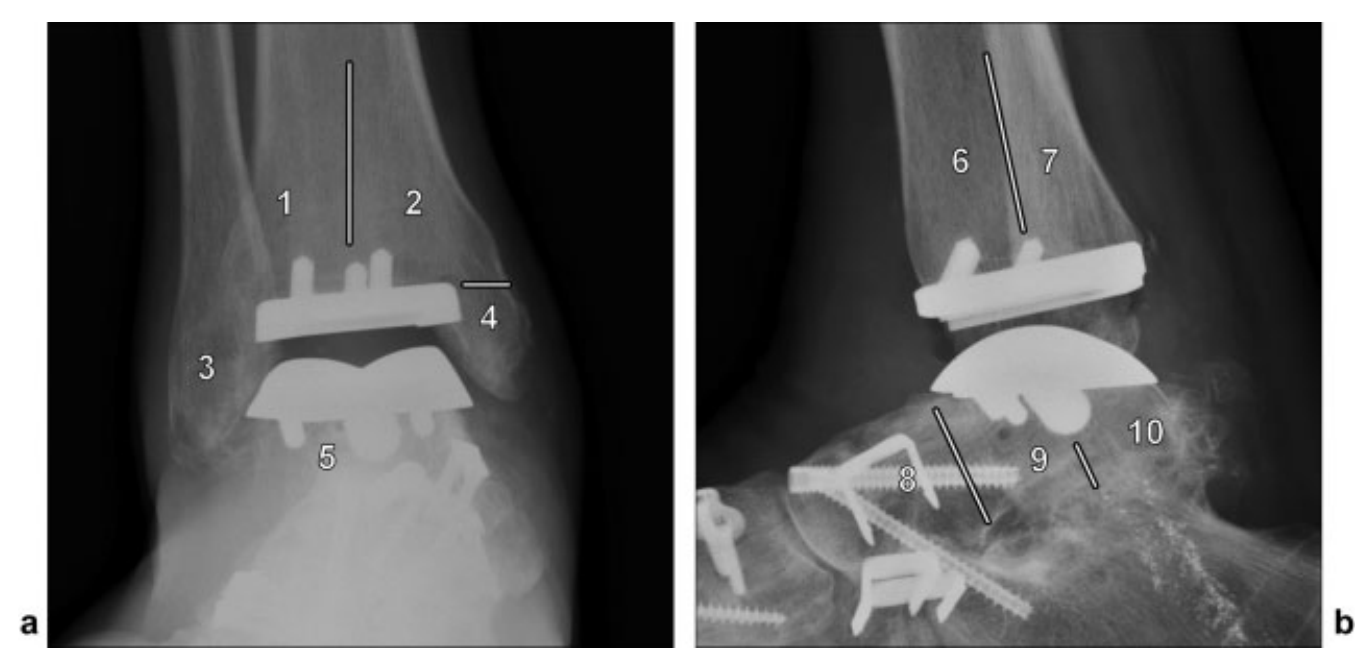

Fig. 13 Besse zonal system for characterizing expansile osteolysis. This system may be more helpful in characterizing the locations of periprosthetic cyst-like lesions. (a) On an anteroposterior radiograph of the ankle, the joint is divided into five zones including the lateral tibia, media tibia, lateral malleolus, medial malleolus, and area under the talar implant at the metal-bone interface. (b) On a lateral radiograph, the joint is also divided into five zones: the anterior tibia, posterior tibia, posterior implant-bone interface, anterior implant/bone interface, and the talar head/neck junction. 

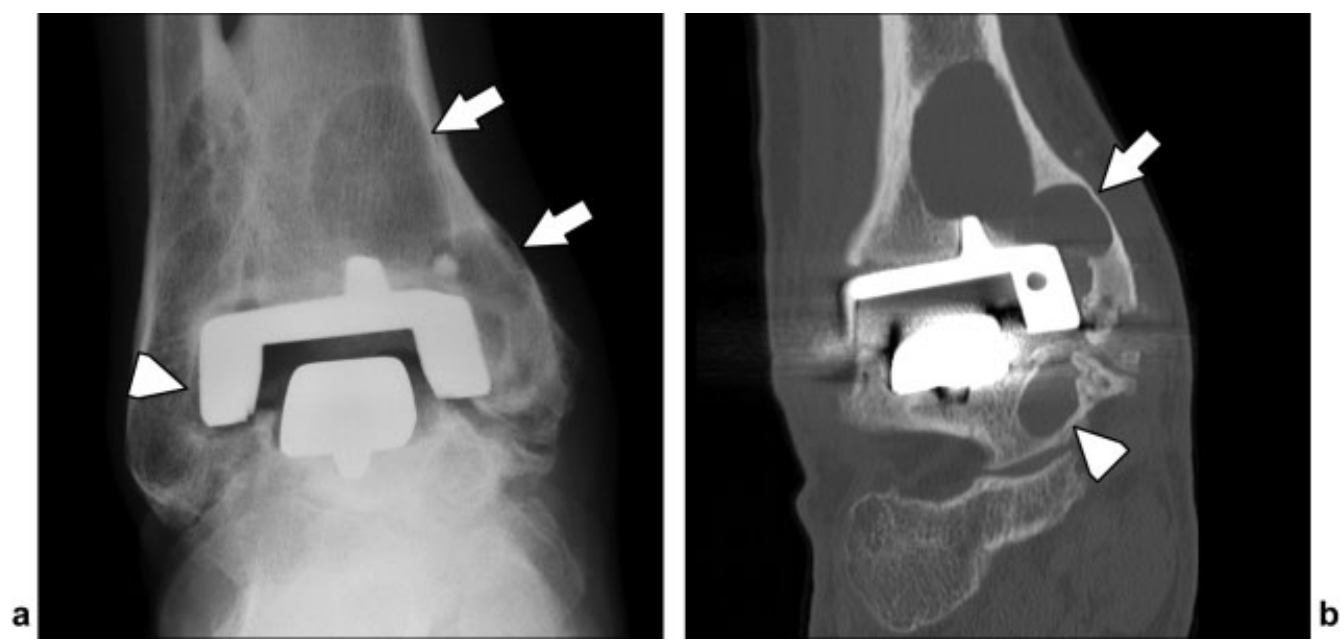

Fig. 14 Computed tomography (CT) showing aseptic loosening and expansile osteolysis in a 64-year-old man with persistent ankle pain following total ankle arthroplasty with the Agility device. (a) Initial anteroposterior radiograph of the ankle shows expansile periprosthetic lucency along the medial distal tibial metaphysis and medial malleolus with thinning of the overlying cortex (arrow). There is excessive tibiotalar crowning that often leads to scalloping of the lateral malleolus (arrowhead). CT was performed to better characterize the area of abnormality at the bone-prosthesis interface. (b) Coronal CT reformatted image re-demonstrates the periprosthetic ballooning osteolysis in the tibia (arrow) along with another area in the medial talar body (arrowhead) that was not as well seen on the radiographs.

MRI of TAA is much less common than of total hip or knee arthroplasty, and little in the literature specifically addresses MRI optimization of TAA. In part this may be due to the relative infrequency of TAAs performed compared with total hip or knee arthroplasty. However, many of the imaging findings suggesting loosening are usually seen on radiography and CT when needed. MRI may be most helpful in looking for joint effusions and synovial proliferation, along with periprosthetic fluid collections. Additionally, MRI may help assess adjacent soft tissue structures, such as the surrounding ligaments and tendons. ${ }^{98}$ As with CT, MRI of metallic devices can produce significant artifacts that limit its ability to characterize the adjacent bone and soft tissues, and several techniques have been used to reduce the degree of artifact to detect areas of expansile periprosthetic osteolysis. These include orienting the long axis of the device along the long axis of the main magnetic field, imaging on lower field-strength magnets with strong gradients, using high bandwidth sequences, substituting short tau inversion recovery sequences for chemically selective, fat-suppressed, fluid-sensitive sequences, and using thin section imaging. ${ }^{108}$ Several vendor-specific metal artifact reduction techniques have been very helpful in significantly reducing metal artifact around orthopaedic devices, allowing better assessment of the periprosthetic tissues. ${ }^{109,110}$ Hayter et al published data on 122 patients with hip, knee, and shoulder arthroplasties in which they found the multi-acquisition variableresonance image combination (MAVRIC) sequence outperformed traditional fast spin-echo (FSE) techniques for assessing the synovium in the affected joint, as well as the prosthesis-bone interface. ${ }^{111}$ Recently, de Cesar Netto et al published a report on 40 patients with TAA comparing a compressed sensing slice encoding in metal artifact reduction (CS-SEMAC) technique with traditional high bandwidth techniques. They found that CS-SEMAC significantly improved detection and diagnostic confidence in the detection of periprosthetic marrow edema, osteolysis, and fractures, as well as synovitis and tendinopathy. ${ }^{112}$ These techniques, either in combination with or instead of existing FSE sequences, may help establish a larger future role for MRI in assessing painful TAAs.

US has a much more restricted role in assessing TAA compared with other modalities because it has a limited ability to characterize the periprosthetic bone. Unlike with other imaging modalities, the metallic devices do not produce significant artifacts that obscure the adjacent soft tissues, and US is particularly helpful in evaluating the surrounding soft tissues, such as the joint capsule and its recesses for the presence of an effusion or synovitis, or

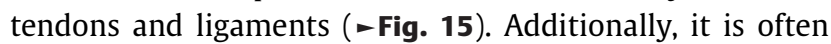
used to detect periprosthetic fluid collections and to provide imaging guidance for diagnostic aspirations when abscess or septic arthritis is of concern. ${ }^{113}$

Scintigraphy, using either Tc-99m methylene diphosphonate (MDP) or Tc-99m hydroxymethylene diphosphonate (HDP), can be helpful to assess patients with pain following joint replacement if other imaging modalities do not clearly demonstrate the cause of symptoms. Imaging consists of initial planar anterior and posterior blood pool images if there is concern for infection or inflammation along with static anterior, posterior, and lateral images after a 5-minute delay. Areas of increased radiotracer uptake indicate areas of increased bone turnover. ${ }^{14,115}$ Many practices have also included fusion SPECT/CT imaging if the initial planar images are either nondiagnostic or do not clearly show which areas demonstrate increased bone turnover. ${ }^{116}$ SPECT/CT has the benefit of greater accuracy and localization with marginal increase in radiation dose compared with planar images.

Much of the literature regarding the use of bone scintigraphy has been performed for total knee and hip 

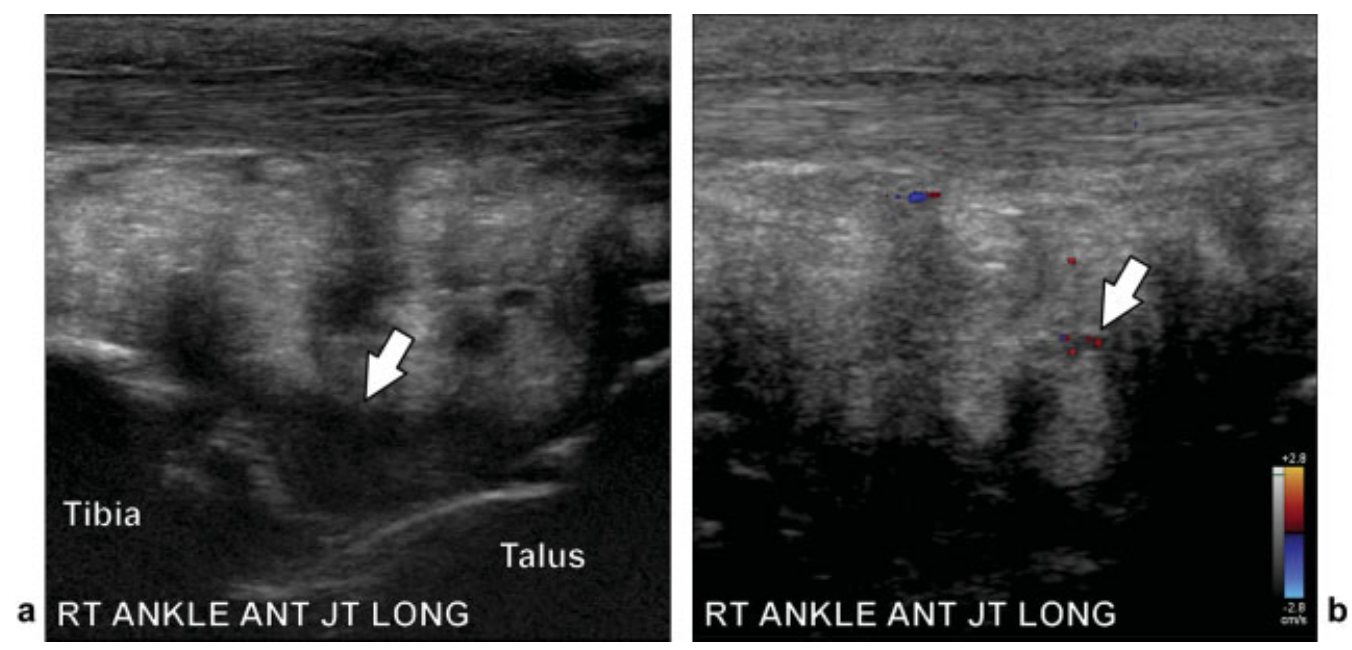

Fig. 15 Periprosthetic synovitis in a 55-year-old man who had persistent diffuse ankle pain following Salto Talaris total ankle arthroplasty 6 months earlier (continued for - Fig. 4). Ultrasound was performed to assess for periprosthetic effusion that could indicate infection. (a) On long-axis gray-scale sonographic image, the patient had hypoechoic material distending the anterior tibiotalar joint recess (arrow), while on (b) color Doppler image there was mild hyperemia (arrow). This study was performed on the patient described in - Fig. 4, in which subsequent computed tomography demonstrated expansile osteolysis along the talar component, particularly posteriorly.

arthroplasty, and these data have been used clinically in assessing TAAs. Increased radiotracer uptake has been used to detect areas of aseptic loosening around knee arthroplasties, and the greatest benefit of bone scintigraphy is its negative predictive value. ${ }^{117}$ Mildly increased radiotracer uptake has been noted around total knee and hip arthroplasties for up to 12 months following surgery. However, this should not increase postoperatively on serial examinations. Recent published work by Mason et al that examined the SPECT/CT findings in 14 patients with persistent pain following TAA found a high rate of increased radiotracer uptake along the medial talar component and a lower rate of tracer uptake along the medial tibial component that was not seen radiographically. The authors believed this may represent signs of aseptic loosening. ${ }^{118}$

Areas of increased radiotracer uptake on bone scintigraphy only indicate active bone turnover and are not specific for a particular pathology, and targeted nuclear medicine imaging using radiolabeled leukocytes may provide greater accuracy in detecting periprosthetic joint infections. However, it was reported that indium-111-labeled leukocyte studies on their own have relatively low sensitivity and specificity for diagnosing musculoskeletal infections, and the combination of indium-111-labeled leukocyte imaging and Tc-99m sulfur colloid imaging of the bone marrow has been helpful in detecting infections of bone. A result that is positive for periprosthetic infection using this approach consists of a mismatch between the labeled leukocyte study and the bone marrow imaging. On the labeled leukocyte study there would be increased radiotracer uptake around the prosthesis indicating accumulated leukocytes. However, there would be a photopenic area on the sulfur colloid scan that represents a suppressed response of the bone marrow phagocytic activity that occurs in response to infection. This combination approach has a reported accuracy of 88 to $98 \%$ in detecting periprosthetic joint infections. ${ }^{119,120}$

\section{Conclusion}

TAA is becoming a more widely used device in the treatment of end-stage ankle arthropathy, and it is an alternative surgical option to ankle arthrodesis in many institutions for appropriately selected patients. Several device designs are available, and imagers asked to assess TAAs should be familiar with the imaging appearances and common complications of the most frequently used types. Imaging is critical in the early detection of postoperative complications, which can help guide clinical management. Serial conventional radiography is the imaging modality of choice to establish the baseline appearance of individual patients and to detect subtle changes in implant positioning that can indicate developing device failure. CT is most often used to evaluate expansile periprosthetic osteolysis; MRI or US may be useful to assess surrounding soft tissue stabilizers or periprosthetic fluid collections.

Conflict of Interest

None declared.

\section{References}

1 Cushnaghan J, Dieppe P. Study of 500 patients with limb joint osteoarthritis. I. Analysis by age, sex, and distribution of symptomatic joint sites. Ann Rheum Dis 1991;50(01):8-13

2 Barg A, Pagenstert GI, Hügle T, et al. Ankle osteoarthritis: etiology, diagnostics, and classification. Foot Ankle Clin 2013; 18(03):411-426

3 Glazebrook M, Daniels T, Younger A, et al. Comparison of healthrelated quality of life between patients with end-stage ankle and hip arthrosis. J Bone Joint Surg Am 2008;90(03):499-505

4 Delco ML, Kennedy JG, Bonassar LJ, Fortier LA. Post-traumatic osteoarthritis of the ankle: a distinct clinical entity requiring new research approaches. J Orthop Res 2017;35(03):440-453 
5 Goldberg AJ, MacGregor A, Dawson J, et al. The demand incidence of symptomatic ankle osteoarthritis presenting to foot \& ankle surgeons in the United Kingdom. Foot 2012;22(03):163-166

6 Daniels TR, Younger AS, Penner M, et al. Intermediate-term results of total ankle replacement and ankle arthrodesis: a COFAS multicenter study. J Bone Joint Surg Am 2014;96(02): 135-142

7 Haddad SL, Coetzee JC, Estok R, Fahrbach K, Banel D, Nalysnyk L. Intermediate and long-term outcomes of total ankle arthroplasty and ankle arthrodesis. A systematic review of the literature. J Bone Joint Surg Am 2007;89(09):1899-1905

8 Raikin SM, Rasouli MR, Espandar R, Maltenfort MG. Trends in treatment of advanced ankle arthropathy by total ankle replacement or ankle fusion. Foot Ankle Int 2014;35(03):216-224

9 Saltzman CL, Mann RA, Ahrens JE, et al. Prospective controlled trial of STAR total ankle replacement versus ankle fusion: initial results. Foot Ankle Int 2009;30(07):579-596

10 Lord G, Marotte JH. Total ankle prosthesis. Technic and 1st results. Apropos of 12 cases [in French]. Rev Chir Orthop Repar Appar Mot 1973;59(02):139-151

11 Gougoulias N, Maffulli N. History of total ankle replacement. Clin Podiatr Med Surg 2013;30(01):1-20

12 Rybalko D, Schwarzman G, Moretti V. Recent national trends and outcomes in total ankle arthroplasty in the United States. J Foot Ankle Surg 2018;57(06):1092-1095

13 Syed F, Ugwuoke A. Ankle arthroplasty: a review and summary of results from joint registries and recent studies. EFORT Open Rev 2018;3(06):391-397

14 Roukis TS, Prissel MA. Registry data trends of total ankle replacement use. J Foot Ankle Surg 2013;52(06):728-735

15 Terrell RD, Montgomery SR, Pannell WC, et al. Comparison of practice patterns in total ankle replacement and ankle fusion in the United States. Foot Ankle Int 2013;34(11):1486-1492

16 US Food and Drug Administration. Medical Device Databases. https://www.accessdata.fda.gov/SCRIPTS/cdrh/devicesatfda/ index.cfm. Accessed September 27, 2018

17 Lord G, Marotte JH. L'arthroplastie totale de cheville. Expérience sur 10 ans, à propos de 25 observations personnelles. Rev Chir Orthop 1980;66:527-530

18 Saltzman CL. Perspective on total ankle replacement. Foot Ankle Clin 2000;5(04):761-775

19 Buchholz HW, Engelbrecht E, Siegel A. Totale Sprunggelenkprothese Modell “St. Georg.”. Chirurg 1973;44:241-244

20 Kempson GE, Freeman MAR, Tuke MA. Engineering considerations in the design of an ankle joint. Biomed Eng 1975;10(05): $166-171,80$

21 Guyer AJ, Richardson G. Current concepts review: total ankle arthroplasty. Foot Ankle Int 2008;29(02):256-264

22 Wynn AH, Wilde AH. Long-term follow-up of the Conaxial (BeckSteffee) total ankle arthroplasty. Foot Ankle 1992;13(06): 303-306

23 Newton SE. An artificial ankle joint. Clin Orthop Relat Res 1979; (142):141-145

24 Dini AA, Bassett FH III. Evaluation of the early result of Smith total ankle replacement. Clin Orthop Relat Res 1980;(146): 228-230

25 Kirkup J. Richard Smith ankle arthroplasty. J R Soc Med 1985;78 (04):301-304

26 Takakura Y, Tanaka Y, Sugimoto K, Tamai S, Masuhara K. Ankle arthroplasty. A comparative study of cemented metal and uncemented ceramic prostheses. Clin Orthop Relat Res 1990;(252): 209-216

27 Scholz KC. Total ankle arthroplasty using biological fixation components compared to ankle arthrodesis. Orthopedics 1987;10(01):125-131

28 Mulcahy H, Chew FS. Current concepts in total ankle replacement for radiologists: features and imaging assessment. AJR Am J Roentgenol 2015;205(05):1038-1047
29 Knecht SI, Estin M, Callaghan JJ, et al. The Agility total ankle arthroplasty. Seven- to sixteen-year follow-up. J Bone Joint Surg Am 2004;86-A(06):1161-1171

30 Spirt AA, Assal M, Hansen ST Jr. Complications and failure after total ankle arthroplasty. J Bone Joint Surg Am 2004;86-A(06): $1172-1178$

31 Cerrato R, Myerson MS. Total ankle replacement: the Agility LP prosthesis. Foot Ankle Clin 2008;13(03):485-494, ix

32 McCollum G, Myerson MS. Failure of the Agility total ankle replacement system and the salvage options. Clin Podiatr Med Surg 2013;30(02):207-223

33 DeVries JG, Scott RT, Berlet GC, Hyer CF, Lee TH, DeOrio JK. Agility to INBONE: anterior and posterior approaches to the difficult revision total ankle replacement. Clin Podiatr Med Surg 2013;30 (01):81-96

34 Leszko F, Komistek RD, Mahfouz MR, et al. In vivo kinematics of the Salto total ankle prosthesis. Foot Ankle Int 2008;29(11): 1117-1125

35 Kofoed H. Scandinavian Total Ankle Replacement (STAR). Clin Orthop Relat Res 2004;(424):73-79

36 Robati S, Salih A, Ghosh K, Vinayakam P. The Scandinavian Total Ankle Replacement and the ideal biomechanical requirements of ankle replacements. J Orthop 2015;13(01):48-51

$37 \mathrm{Yu} \mathrm{JJ}$, Sheskier S. Total ankle replacement-evolution of the technology and future applications. Bull Hosp Jt Dis (2013) 2014;72(01):120-128

38 Reiley MA. INBONE total ankle replacement. Foot Ankle Spec 2008;1(05):305-308

39 Reiley MA. Total ankle arthroplasty with bone defects. Foot Ankle Spec 2009;2(01):32-34

40 Lewis JS Jr, Green CL, Adams SB Jr, Easley ME, DeOrio JK, Nunley JA. Comparison of first- and second-generation fixed-bearing total ankle arthroplasty using a modular intramedullary tibial component. Foot Ankle Int 2015;36(08):881-890

41 Adams SB Jr, Demetracopoulos CA, Queen RM, Easley ME, DeOrio JK, Nunley JA. Early to mid-term results of fixed-bearing total ankle arthroplasty with a modular intramedullary tibial component. J Bone Joint Surg Am 2014;96(23):1983-1989

42 Penner M, Davis WH, Wing K, Bemenderfer T, Waly F, Anderson RB. The Infinity Total Ankle System: early clinical results with 2- to 4year follow-up. Foot Ankle Spec 2018;11(04):1938640018777601

43 Chou LB, Coughlin MT, Hansen S Jr, et al. Osteoarthritis of the ankle: the role of arthroplasty. J Am Acad Orthop Surg 2008;16 (05):249-259

44 Wood PL, Deakin S. Total ankle replacement. The results in 200 ankles. J Bone Joint Surg Br 2003;85(03):334-341

45 Wood PL, Crawford LA, Suneja R, Kenyon A. Total ankle replacement for rheumatoid ankle arthritis. Foot Ankle Clin 2007;12 (03):497-508, vii

46 Eichinger S, Forst R, Kindervater M. Indications and alternatives for arthroplasty in young patients [in German]. Orthopade 2007; 36(04):311-324

47 Barg A, Knupp M, Hintermann B. Simultaneous bilateral versus unilateral total ankle replacement: a patient-based comparison of pain relief, quality of life and functional outcome. J Bone Joint Surg Br 2010;92(12):1659-1663

48 Kim BS, Knupp M, Zwicky L, Lee JW, Hintermann B. Total ankle replacement in association with hindfoot fusion: outcome and complications. J Bone Joint Surg Br 2010;92(11):1540-1547

49 Neufeld SK, Lee TH. Total ankle arthroplasty: indications, results, and biomechanical rationale. Am J Orthop 2000;29(08):593-602

50 Gill LH. Challenges in total ankle arthroplasty. Foot Ankle Int 2004;25(04):195-207

51 Doets HC, Brand R, Nelissen RG. Total ankle arthroplasty in inflammatory joint disease with use of two mobile-bearing designs. J Bone Joint Surg Am 2006;88(06):1272-1284

$52 \mathrm{Kim}$ BS, Lee JW. Total ankle replacement for the varus unstable osteoarthritic ankle. Tech Foot Ankle 2010;9:157-167 
53 Brunner S, Knupp M, Hintermann B. Total ankle replacement for the valgus unstable osteoarthritic ankle. Tech Foot Ankle 2010; 9:165-174

54 Hobson SA, Karantana A, Dhar S. Total ankle replacement in patients with significant pre-operative deformity of the hindfoot. J Bone Joint Surg Br 2009;91(04):481-486

55 Coetzee JC, Castro MD. Accurate measurement of ankle range of motion after total ankle arthroplasty. Clin Orthop Relat Res 2004;(424):27-31

56 Karantana A, Hobson S, Dhar S. The Scandinavian Total Ankle Replacement: survivorship at 5 and 8 years comparable to other series. Clin Orthop Relat Res 2010;468(04):951-957

57 Lee WT, Myerson MS, Grosshand KT. What variables influence final range of motion following total ankle arthroplasty. Foot and Ankle Orthopaedics 2016;1(1);http://doi.org/10.1177/ 2473011416500027

58 Bai LB, Lee KB, Song EK, Yoon TR, Seon JK. Total ankle arthroplasty outcome comparison for post-traumatic and primary osteoarthritis. Foot Ankle Int 2010;31(12):1048-1056

59 Berlet GC, Penner MJ, Lancianese S, Stemniski PM, Obert RM. Total ankle arthroplasty accuracy and reproducibility using preoperative CT scan-derived, patient-specific guides. Foot Ankle Int 2014;35(07):665-676

60 Hsu AR, Davis WH, Cohen BE, Jones CP, Ellington JK, Anderson RB. Radiographic outcomes of preoperative CT scan-derived patientspecific total ankle arthroplasty. Foot Ankle Int 2015;36(10): 1163-1169

61 Werner S, Brage M. Comparison of two operative techniques for total ankle arthroplasty: intramedullary referencing vs CT scanderived patient-specific guides. Foot Ankle Orthop 2016;1(1) Available at: https://www.aofas.org/PRC/meeting/Documents/ 2011.pdf

62 Lawton CD, Butler BA, Dekker RG II, Prescott A, Kadakia AR. Total ankle arthroplasty versus ankle arthrodesis-a comparison of outcomes over the last decade. J Orthop Surg Res 2017;12(01):76

63 Jauregui JJ, Cherian JJ, Pierce TP, Beaver WB, Issa K, Mont MA. Long-term survivorship and clinical outcomes following total knee arthroplasty. J Arthroplasty 2015;30(12):2164-2166

$64 \mathrm{Chu}$ CR. Short-term analysis vs long-term data on total hip replacement survivorship. JAMA Surg 2015;150(10):989

65 Sadoghi P, Liebensteiner M, Agreiter M, Leithner A, Böhler N, Labek G. Revision surgery after total joint arthroplasty: a complication-based analysis using worldwide arthroplasty registers. J Arthroplasty 2013;28(08):1329-1332

66 Gougoulias N, Khanna A, Maffulli N. How successful are current ankle replacements?: a systematic review of the literature Clin Orthop Relat Res 2010;468(01):199-208

67 Barg A, Zwicky L, Knupp M, Henninger HB, Hintermann B. HINTEGRA total ankle replacement: survivorship analysis in 684 patients. J Bone Joint Surg Am 2013;95(13):1175-1183

68 Pinar N, Vernet E, Bizot P, Brilhault J. Total ankle arthroplastytotal ankle arthroplasty in western France: influence of volume on complications and clinical outcome. Orthop Traumatol Surg Res 2012;98(4, Suppl):S26-S30

69 Labek G, Todorov S, Iovanescu L, Stoica CI, Böhler N. Outcome after total ankle arthroplasty-results and findings from worldwide arthroplasty registers. Int Orthop 2013;37(09):1677-1682

70 Barnett $\mathrm{CH}$, Napier JR. The axis of rotation at the ankle joint in man; its influence upon the form of the talus and the mobility of the fibula. J Anat 1952;86(01):1-9

71 Hicks JH. The mechanics of the foot. I. The joints. J Anat 1953;87 (04):345-357

72 Evanski PH, Waugh TR. Management of arthritis of the ankle. An alternative of arthrodesis. Clin Orthop Relat Res 1977;(122): 110-115

73 Pappas M, Buechel FF, DePalma AF. Cylindrical total ankle joint replacement: surgical and biomechanical rationale. Clin Orthop Relat Res 1976;(118):82-92
74 Vickerstaff JA, Miles AW, Cunningham JL. A brief history of total ankle replacement and a review of the current status. Med Eng Phys 2007;29(10):1056-1064

75 Lee AY, Ha AS, Petscavage JM, Chew FS. Total ankle arthroplasty: a radiographic outcome study. AJR Am J Roentgenol 2013;200 (06):1310-1316

76 Glazebrook MA, Arsenault K, Dunbar M. Evidence-based classification of complications in total ankle arthroplasty. Foot Ankle Int 2009;30(10):945-949

77 Bestic JM, Peterson JJ, DeOrio JK, Bancroft LW, Berquist TH, Kransdorf MJ. Postoperative evaluation of the total ankle arthroplasty. AJR Am J Roentgenol 2008;190(04):1112-1123

78 Zaidi R, Cro S, Gurusamy K, et al. The outcome of total ankle replacement: a systematic review and meta-analysis. Bone Joint J 2013;95-B(11):1500-1507

79 Espinosa N, Klammer G, Wirth SH. Osteolysis in total ankle replacement: how does it work? Foot Ankle Clin 2017;22(02): 267-275

80 Hsu AR, Haddad SL, Myerson MS. Evaluation and management of the painful total ankle arthroplasty. J Am Acad Orthop Surg 2015;23(05):272-282

81 Arcângelo J, Guerra-Pinto F, Pinto A, Grenho A, Navarro A, Martin Oliva X. Peri-prosthetic bone cysts after total ankle replacement. A systematic review and meta-analysis. Foot Ankle Surg 2017: S1268-7731(17)31347-4

82 van Wijngaarden R, van der Plaat L, Nieuwe Weme RA, Doets HC, Westerga J, Haverkamp D. Etiopathogenesis of osteolytic cysts associated with total ankle arthroplasty, a histological study. Foot Ankle Surg 2015;21(02):132-136

83 Singh G, Reichard T, Hameister R, et al. Ballooning osteolysis in 71 failed total ankle arthroplasties. Acta Orthop 2016;87(04): 401-405

84 Li SY, Myerson MS. Management of talar component subsidence. Foot Ankle Clin 2017;22(02):361-389

85 Mulcahy H, Chew FS. Current concepts in total ankle replacement for radiologists: complications. AJR Am J Roentgenol 2015; 205(06):1244-1250

86 Jonck JH, Myerson MS. Revision total ankle replacement. Foot Ankle Clin 2012;17(04):687-706

87 Alrashidi Y, Galhoum AE, Wiewiorski M, et al. How to diagnose and treat infection in total ankle arthroplasty. Foot Ankle Clin 2017;22(02):405-423

88 Manegold S, Haas NP, Tsitsilonis S, Springer A, Märdian S, Schaser KD. Periprosthetic fractures in total ankle replacement: classification system and treatment algorithm. J Bone Joint Surg Am 2013;95(09):815-820, S1-S3

89 Brunner S, Barg A, Knupp M, et al. The Scandinavian Total Ankle Replacement: long-term, eleven to fifteen-year, survivorship analysis of the prosthesis in seventy-two consecutive patients. J Bone Joint Surg Am 2013;95(08):711-718

90 Manegold S, Springer A, Landvoigt K, Tsitsilonis S. Heterotopic ossification after total ankle replacement: the role of prosthesis alignment. Foot Ankle Surg 2017;23(02):122-127

91 Dahabreh Z, Gonsalves S, Monkhouse R, Harris NJ. Extrusion of metal radiological marker from a total ankle replacement insert: a case report. J Foot Ankle Surg 2006;45(03):185-189

92 Kerkhoff YR, Kosse NM, Metsaars WP, Louwerens JW. Long-term functional and radiographic outcome of a mobile bearing ankle prosthesis. Foot Ankle Int 2016;37(12):1292-1302

93 Coester LM, Saltzman CL, Leupold J, Pontarelli W. Long-term results following ankle arthrodesis for post-traumatic arthritis. J Bone Joint Surg Am 2001;83-A(02):219-228

94 Fuchs S, Sandmann C, Skwara A, Chylarecki C. Quality of life 20 years after arthrodesis of the ankle. A study of adjacent joints. J Bone Joint Surg Br 2003;85(07):994-998

95 Morrey BF, Wiedeman GP Jr. Complications and long-term results of ankle arthrodeses following trauma. J Bone Joint Surg Am 1980;62(05):777-784 
96 Barg A, Wimmer MD, Wiewiorski M, Wirtz DC, Pagenstert GI, Valderrabano V. Total ankle replacement. Dtsch Arztebl Int 2015; 112(11):177-184

97 Lee KJ, Wang SH, Lee GW, Lee KB. Accuracy assessment of measuring component position after total ankle arthroplasty using a conventional method. J Orthop Surg Res 2017;12(01): 115

98 Kim DR, Choi YS, Potter HG, et al. Total ankle arthroplasty: an imaging overview. Korean J Radiol 2016;17(03):413-423

99 Pyevich MT, Saltzman CL, Callaghan JJ, Alvine FG. Total ankle arthroplasty: a unique design. Two to twelve-year follow-up. J Bone Joint Surg Am 1998;80(10):1410-1420

100 Lohmann CH, Rampal S, Lohrengel M, Singh G. Imaging in periprosthetic assessment: an orthopaedic perspective. EFORT Open Rev 2017;2(05):117-125

101 Besse JL, Brito N, Lienhart C. Clinical evaluation and radiographic assessment of bone lysis of the AES total ankle replacement. Foot Ankle Int 2009;30(10):964-975

102 Hanna RS, Haddad SL, Lazarus ML. Evaluation of periprosthetic lucency after total ankle arthroplasty: helical CT versus conventional radiography. Foot Ankle Int 2007;28(08):921-926

103 Kohonen Ia, Koivu H, Pudas T, Tiusanen H, Vahlberg T, Mattila K. Does computed tomography add information on radiographic analysis in detecting periprosthetic osteolysis after total ankle arthroplasty? Foot Ankle Int 2013;34(02):180-188

104 Viste A, Al Zahrani N, Brito N, Lienhart C, Fessy MH, Besse JL. Periprosthetic osteolysis after AES total ankle replacement: conventional radiography versus CT-scan. Foot Ankle Surg 2015;21(03):164-170

105 Kohonen Ia, Koivu H, Vahlberg T, Larjava H, Mattila K. Total ankle arthroplasty: optimizing computed tomography imaging protocol. Skeletal Radiol 2013;42(11):1507-1513

106 Pessis E, Campagna R, Sverzut JM, et al. Virtual monochromatic spectral imaging with fast kilovoltage switching: reduction of metal artifacts at CT. Radiographics 2013;33(02):573-583

107 Khodarahmi I, Haroun RR, Lee M, et al. Metal artifact reduction computed tomography of arthroplasty implants: effects of combined modeled iterative reconstruction and dual-energy virtual monoenergetic extrapolation at higher photon energies. Invest Radiol 2018;53(12):728-735
108 Lee MJ, Kim S, Lee SA, et al. Overcoming artifacts from metallic orthopedic implants at high-field-strength MR imaging and multi-detector CT. Radiographics 2007;27(03):791-803

109 Koff MF, Burge AJ, Koch KM, Potter HG. Imaging near orthopedic hardware. J Magn Reson Imaging 2017;46(01):24-39

110 Berkowitz JL, Potter HG. Advanced MRI techniques for the hip joint: focus on the postoperative hip. AJR Am J Roentgenol 2017; 209(03):534-543

111 Hayter CL, Koff MF, Shah P, Koch KM, Miller TT, Potter HG. MRI after arthroplasty: comparison of MAVRIC and conventional fast spinecho techniques. AJR Am J Roentgenol 2011;197(03):W405-11

112 de Cesar Netto C, Fonseca LF, Fritz B, et al. Metal artifact reduction MRI of total ankle arthroplasty implants. Eur Radiol 2018;28(05):2216-2227

113 Awan O, Chen L, Resnik CS. Imaging evaluation of complications of hip arthroplasty: review of current concepts and imaging findings. Can Assoc Radiol J 2013;64(04):306-313

114 van der Bruggen W, Hirschmann MT, Strobel K, et al. SPECT/CT in the postoperative painful knee. Semin Nucl Med 2018;48(05): 439-453

115 Van den Wyngaert T, Paycha F, Strobel K, et al. SPECT/CT in postoperative painful hip arthroplasty. Semin Nucl Med 2018;48 (05):425-438

116 Hirschmann MT, Henckel J, Rasch H. SPECT/CT in patients with painful knee arthroplasty-what is the evidence? Skeletal Radiol 2013;42(09):1201-1207

117 Hirschmann MT, Amsler F, Rasch H. Clinical value of SPECT/CT in the painful total knee arthroplasty (TKA): a prospective study in a consecutive series of 100 TKA. Eur J Nucl Med Mol Imaging 2015;42(12):1869-1882

118 Mason LW, Wyatt J, Butcher C, Wieshmann H, Molloy AP. Singlephoton-emission computed tomography in painful total ankle replacements. Foot Ankle Int 2015;36(06):635-640

119 Van Acker F, Nuyts J, Maes A, et al. FDG-PET, 99mtc-HMPAO white blood cell SPET and bone scintigraphy in the evaluation of painful total knee arthroplasties. Eur J Nucl Med 2001;28(10):1496-1504

120 Palestro CJ, Love C, Tronco GG, Tomas MB, Rini JN. Combined labeled leukocyte and technetium $99 \mathrm{~m}$ sulfur colloid bone marrow imaging for diagnosing musculoskeletal infection. Radiographics 2006;26(03):859-870 